MICHIGAN RETIREMENT AND DISABILITY RESEARCH CENTER UNIVERSITY OF MICHIGAN

Promoting research on retirement, disability, and Social Security policy

\title{
Nursing Homes in Equilibrium: Implications for Long-term Care Policies
}

Tatyana Koreshkova and Minjoon Lee

MRDRC WP 2020-414

UM20-13 


\section{Nursing Homes in Equilibrium: Implications for Long-term Care Policies}

Tatyana Koreshkova

Concordia University
Minjoon Lee

Carleton University

\section{September 2020}

Michigan Retirement and Disability Research Center, University of Michigan, P.O. Box 1248. Ann Arbor, Ml 48104, mrdrc.isr.umich.edu, (734) 615-0422

\section{Acknowledgements}

The research reported herein was performed pursuant to a grant from the U.S. Social Security Administration (SSA) funded as part of the Retirement and Disability Research Consortium through the University of Michigan Retirement and Disability Research Center Award RDR18000002-02. The opinions and conclusions expressed are solely those of the author(s) and do not represent the opinions or policy of SSA or any agency of the federal government. Neither the United States government nor any agency thereof, nor any of their employees, makes any warranty, express or implied, or assumes any legal liability or responsibility for the accuracy, completeness, or usefulness of the contents of this report. Reference herein to any specific commercial product, process or service by trade name, trademark, manufacturer, or otherwise does not necessarily constitute or imply endorsement, recommendation or favoring by the United States government or any agency thereof.

\section{Regents of the University of Michigan}

Jordan B. Acker; Huntington Woods; Michael J. Behm, Grand Blanc; Mark J. Bernstein, Ann Arbor; Paul W. Brown, Ann Arbor; Shauna Ryder Diggs, Grosse Pointe; Denise llitch, Bingham Farms; Ron Weiser, Ann Arbor; Katherine E. White, Ann Arbor; Mark S. Schlissel, ex officio 


\title{
Nursing Homes in Equilibrium: Implications for Long-term Care Policies
}

\begin{abstract}
We build an equilibrium model of the market for nursing home care with decision-makers on both sides of the market. The nursing home demand arises as a result of stochastic dynamic optimizations by households heterogeneous in age, health, wealth; and the cost of home-andcommunity-based care. On the supply side, locally competitive nursing homes decide prices and care intensity. The government pays for the long-term care of the poorest. We estimate the model parameters using Health and Retirement Survey and simulate the model to quantitatively evaluate the effects of long-term care policies on prices, intensities, care allocation, and welfare.
\end{abstract}

\section{Citation}

Koreshkova, Tatyana and Minjoon Lee. 2020. "Nursing Homes in Equilibrium: Implications for Long-term Care Policies.” Ann Arbor, MI. University of Michigan Retirement and Disability Research Center (MRDRC) Working Paper; MRDRC WP 2020-414.

https://mrdrc.isr.umich.edu/publications/papers/pdf/wp414.pdf

\section{Authors' acknowledgements}

We thank the seminar and workshop participants at Concordia University and the Michigan Retirement and Disability Research Center Workshop. 


\section{Introduction}

One of the big triumphs of the last century is the greatly increased human life expectancy. Growing old, however, still often comes with accumulation of difficulties with activities of daily living such as eating, toileting, dressing, bathing, getting in and out of bed, etc. According to the recent estimates by U.S. Department of Health and Human Services (2020), about 70\% of Americans older than 65 develop a severe need for long-term care (LTC) and about half receive paid care over their lifetime. Hurd, Michaud, and Rohwedder (2014) find that more than half of individuals will end up using nursing home care after age 50. Long-term care is expensive: According to Genworth (2019), the annual cost of a nursing home stay in 2019 is over $\$ 100 \mathrm{~K}$ for a private room and over $\$ 90 \mathrm{~K}$ for a semi-private room; in-home care costs more than $\$ 20$ per hour. The high out-of-pocket cost of long-term care forces a large share of Americans to rely on public long-term services and supports (LTSS) programs, most importantly Medicaid. ${ }^{1}$ In fact, Medicaid pays for about $75 \%$ of nursing home residents and for about as many individuals in home-and-community-based care (HCBC), which further exacerbates the financial burden of public old-age programs, already strained by the population ageing. In this paper, we argue that the effects of public LTSS policies go beyond the budgetary and consumer insurance implications, and have nontrivial effects on the nursing home market. The changes in the market equilibrium, in turn, affect the allocation of care and distribution of welfare gains and losses from the LTSS policies.

\footnotetext{
${ }^{1}$ Medicaid covers $51 \%$ of the total LTSS costs in the U.S. (Kaiser Family Foundation, 2015). Half of Medicaid LTSS enrollees are in nursing homes while the other half uses HCBC. Medicaid nursing home expenditures account for $70 \%$ of total Medicaid LTSS spending (Kaiser Family Foundation, 2016).
} 
We build a dynamic structural model of a nursing home market with an objective to quantitatively evaluate LTSS policies. In our model, demand and supply of nursing home care arise as a results of decision-making by optimizing agents. On the demand side, households, heterogeneous in age, financial resources, health, and family status, make consumption-savings decisions, and those with an LTC need choose to receive care either at a nursing home or in their own home. On the supply side, locally competitive nursing homes decide price and care intensity, taking as given the demand from the households. Medicaid LTSS policy imposes rules on both sides of the market. On the demand side, it determines eligible individuals through means tests and allows them to receive a certain amount of LTSS for free, either at home or in a nursing home. On the supply side, Medicaid reimburses nursing homes at a fixed rate. We show that Medicaid policy targeting either side of the market has important consequences for both households and nursing homes, with nontrivial equilibrium effects on nursing home prices, quality, care allocation, and welfare.

On the demand side, we solve stochastic dynamic problems of retired households. Households face uncertainty about their health, which determines their LTC need, own and spouse mortality, child proximity (for those with children), and LTC preferences. In contrast to the literature on old-age decisions and risks (Kopecky and Koreshkova 2014, Ameriks et al. 2018, among others), we model the choice of care to endogenize nursing home entry: For each period, individuals with LTC needs choose between nursing home care and $\mathrm{HCBC}$. While nursing homes provide fixed intensity of care, households can freely choose HCBC intensity. Although nursing home care is inflexible, the institutional setting allows nursing homes to provide care at a potentially 
lower unit cost compared to HCBC. HCBC's out-of-pocket costs differ across the households: It is relatively low for those with family support from the non-LTC spouse or a nearby child, and it is high for those without family support. Moreover, individuals without family face a substantial fixed cost when using HCBC to outsource basic home production. Poor households eligible for Medicaid decide whether to forfeit their resources and use Medicaid LTSS (for either nursing-home care or HCBC) or pay for the HCBC out of pocket and use low-intensity care. The individual choice of care gives rise to the demand for nursing homes. While the private demand has standard properties, the demand by Medicaid enrollees does not depend on the price and increases in care intensity.

We discipline the model's demand-side parameters with micro-evidence on the LTC usage patterns observed in the data. Using the Health and Retirement Study data, we document the type and care intensity used conditional on age, financial resources, health, and family status. The model equilibrium successfully generates the key documented care patterns. In particular, individuals without family are more likely to reside in a nursing home and nursing home usage is U-shaped in wealth.

On the supply side, we solve a static problem of a nursing home competing in the local market with other nursing homes. Each nursing home faces an identical cost structure: A fixed operational cost and a variable cost of providing care that depends on the number of beds and care intensity. A nursing home decides the out-of-pocket bed price and care intensity to maximize its profits, taking as given the household demand for care, the Medicaid bed-reimbursement rate (set below the out-of-pocket price), as well as competitors' prices and care intensity. Medicaid regulations prohibit denying 
nursing home entry to its enrollees. As a result, nursing homes have a single control the intensity of care — for the number of Medicaid beds and two controls—-the intensity and price - for the number of private beds. Although the private bed's profit margin exceeds that of the Medicaid bed, the relative elasticities of private demand versus Medicaid demand matter when deciding the optimal quantity and allocation of beds. We solve for the Nash equilibrium of the nursing home market, and calibrate the supply-side parameters to match the key statistics from the Pennsylvania Department of Health's Nursing Home Reports. ${ }^{2}$

We use the calibrated model to quantitatively evaluate the efficiency and distributional effects of four LTSS policies. Two of them target the supply side of the nursing home market: (i) a more generous Medicaid nursing home-bed reimbursement and (ii) a nursing home's subsidized entry into a market. The other two target the demand side: (iii) a more generous Medicaid means test for single households and (iv) a HCBC subsidy for individuals with no family support. We show that in every case it is important to capture the impact of the policies on both sides of the market.

A higher Medicaid reimbursement rate increases the return on Medicaid beds. In order to attract more Medicaid residents, nursing homes increase the care intensity. We find that a $10 \%$ increase in the Medicaid reimbursement rate raises the intensity of care by $3 \%$ and the out-of-pocket price by $2 \%$. New Medicaid beds amount to $3.6 \%$ of the baseline number, and crowd out private beds ( $1.9 \%$ of the baseline number). Nursing

2 Online Appendix A in Hackmann (2019) reports that the nursing home market in Pennsylvania is fairly representative of the U.S. nursing home market. Following Hackmann (2019), we model the nursing home market based on observations from one state, instead of conflating nursing home market characteristics across multiple states. The calibration of our model can be easily modified to match observations from other states. 
home profits and Medicaid outlays increase. Households in the middle of the wealth distribution see small benefits from the higher nursing home care intensity. Households in the top wealth quartile see small losses due to higher out-of-pocket price.

A nursing home's subsidized entry into a market increases the local competition. We find that incumbents react to the entry not only by reducing the price by $10.7 \%$, but also by reducing the intensity of care by $7.3 \%$. These nursing home decisions induce movements in and out of institutional care. Wealthier individuals, experiencing welfare gains from the lower price and a larger selection of facilities, leave out-of-pocket HCBC for nursing homes. Individuals in the bottom half of the wealth distribution, experiencing welfare losses due to the lower intensity of nursing home care, free Medicaid beds in favor of Medicaid and out-of-pocket HCBC. This reallocation of care increases the number of out-of-pocket residents by $13.8 \%$ and reduces the number of Medicaid beds by $18.4 \%$ per nursing home: The total number of Medicaid nursing home residents decreases even though there are more nursing homes available.

We then consider a more generous Medicaid policy on the demand side by raising the amount of wealth single individuals are allowed to keep when qualifying for Medicaid — from virtually zero to $\$ 10,000$. We find that nursing homes react to the larger pool of single Medicaid enrollees by increasing the care intensity by $6.7 \%$ ) and further stimulating the demand for Medicaid beds, with the total increase of $34.5 \%$. The $12.9 \%$ higher bed price discourages private residents from staying in nursing homes, reducing their number by $22.1 \%$. Although consumers across the wealth distribution experience welfare gain from this policy (with the largest gains for the middle two 
quartiles), the increase in the Medicaid outlays exceeds the increase in the consumer surplus nearly by a factor of two. Nursing homes experience a small loss.

In our last policy experiment we introduce a $\$ 10,000$ subsidy to the $\mathrm{HCBC}$ for individuals with no family support that allows them to cover half of the fixed HCBC cost. As private residents with no family support leave nursing home for cheaper out-ofpocket $\mathrm{HCBC}$, nursing homes react by reducing both the price $(-4.5 \%)$ and the intensity of care $(-7.7 \%)$. Lower intensity of care makes nursing home less valuable to Medicaid enrollees; as a result, $12.8 \%$ leave their free nursing home beds. We find that more than half of them switch to out-of-pocket $\mathrm{HCBC}$, reducing the Medicaid outlays by $2.7 \%$. Even though nursing homes lose $12 \%$ of their residents, their profits are almost unaffected due to cost savings. Consumers in the bottom wealth quartiles experience welfare gains from more affordable out-of-pocket HCBC; those in the top wealth quartiles experience welfare gains from the cheaper nursing home price.

We find that in all of the above policy experiments the reactions of both sides of the market are important for accurately assessing the aggregate and distributional impact of each policy and even more so for evaluating policy efficiency. To our knowledge, this is the first paper to incorporate into an equilibrium model both a microfounded demand for nursing home care and competitive nursing homes. The analysis that comes closest in spirit to ours is by Hackmann (2019), who structurally estimates an equilibrium model of nursing home market, but with a reduced-form demand for nursing home care.

This paper builds on important existing works on the LTSS policy. Among the studies focusing on the supply side, Nyman (1985), Gertler (1989), Grabowski (2001), 
and Hackmann (2019) study the effects of a Medicaid reimbursement-rate increase; Ching, Hayashi, and Wang (2015) examines the role of the quantity restriction through the certificate-of-needs policy; Hackmann (2019) considers promoting more competition through a nursing home's incentivized entry into a market. Among the studies focusing on the demand side, De Nardi, French, and Jones (2016), Mommaerts (2018), and Achou (2020) study the role of Medicaid generosity for households; Ettner (1994) and Stabile, Laporte, and Coyte (2006) examine Medicaid home-care benefits.

To date, few models study equilibrium on the nursing home market. Ching, Hayashi, and Wang (2015) and Hackmann (2019) structurally estimate both the demand and supply curves of the market and run counterfactual experiments. Compared to these papers, our contributions are twofold. First, while those papers capture $\mathrm{HCBC}$ as an outside option with a constant utility value, we explicitly model the trade-offs households face in choosing between a nursing home and $\mathrm{HCBC}$. As a result, in our analysis, LTSS policies affect how households with different characteristics select into LTC options. Second, unlike these papers, we solve stochastic dynamic optimizations of the entire elderly population. LTSS policies affect households' saving patterns prior to the realization of their LTC needs, which in turn influences the characteristics and decisions of LTC consumers.

This paper also relates to the literature that studies the substitutability between nursing home care and $\mathrm{HCBC}$, where the latter is often supported by family help. Papers that examine this substitutability empirically include Mommaerts (2016), Mommaerts (2018), and Barczyk and Kredler (2019). Barczyk and Kredler (2018) proposes a structural model that captures the strategic motives behind family 
caregiving. Our model contributes to this literature by showing that the substitutability between nursing home care and $\mathrm{HCBC}$, which varies with household characteristics, is a key determinant in the welfare and distributional effects of LTSS policies.

Lastly, this paper also connects to the literature that uses structural models to study old-age risks and decisions, such as precautionary savings (e.g., De Nardi, French, and Jones 2010; Ameriks et al. 2011; Kopecky and Koreshkova 2014; Ameriks et al. forthcoming) and demand for public and private LTC insurance (e.g., Brown and Finkelstein 2008; Ameriks et al. 2018; Braun, Kopecky, and Koreshkova 2019). Our model augments a standard life-cycle model used in this literature with explicit modeling of LTC decisions, both on the extensive margin (the type of care used) and on the intensive margin (the care intensity received at home). We also extend the standard models by incorporating interactions between the demand and supply of long-term care.

The structure of the rest of the paper is as follows. In Section 2, we show the empirical patterns of LTC demand and supply that guide our modeling of both sides of the market. Section 3 presents a stylized, static model of the LTC market to illustrate the main mechanisms at work. Section 4 builds a full-fledged structural model of the LTC market, and Section 5 discusses the calibration strategy. Section 6 shows the outcomes of four LTSS policy experiments. Section 7 concludes.

\section{Empirical patterns of long-term care demand and supply}

In this section, we examine the empirical patterns of LTC demand and supply. Heterogeneity of LTC demand over age, health, family status, and financial resources motivate our structural model of LTC choice. Key empirical facts regarding nursing homes help discipline the supply side of our model. 


\subsection{Demand}

We use the Health and Retirement Study (HRS) data, a biennial survey of a representative sample of the U.S. population older than 50 , to examine the empirical patterns of LTC demand. We analyze both the extensive margin - which households are more likely to use nursing homes versus $\mathrm{HCBC}$ - as well as the intensive margin — the number of care hours they use — of LTC choice. We consider the number of care hours used as the measure of the "intensity" of long-term care in this paper. We use pooled data from waves 2004-2014, where we can find consistent questions in particular on the number of care hours respondents receive when they need help with the activities of daily living (ADLs). We use the sample of respondents in their 80 s, as this is the age range with the largest number of respondents needing help with ADLs.

We define individuals' health status based on how many ADLs they need help with. We use five basic ADLs: eating, bathing, dressing, walking across a room, and getting in or out of bed. We classify those who need help with more than three ADLs as being in "high needs of help with ADLs" (ADLH). Those who need help with one or two ADLs are classified as "low needs of help with ADLs" (ADLL). For the type of care used, individuals who receive help with ADLs but not in a nursing home are considered using HCBC. Lastly, for the number of care hours used, for those on HCBC, we add the number from each helper listed in the HRS. For those in a nursing home, we record it as 2,000 hours per year following the literature (e.g., Mommaerts 2016).

Own health and availability of family support matter significantly for the choice of care type as well as the intensity of care. Table 1's Panel A shows that, unsurprisingly, those who need help with more ADLs receive a larger number of care hours. The care 
hours under ADLH is three times larger than under ADLL at the median; the mean is twice as large. Own health also affects the care type used. Nursing homes typically do not provide much flexibility in the care set up. Their set up is mostly calibrated for those needing relatively intensive care, which is not an attractive option for those who can manage to do three or more ADLs on their own. Hence, the vast majority use HCBC under ADLL, while about one-third enter a nursing home under ADLH.

Conditional on own health, availability of family support also affects individuals' choices. We classify those with (i) a living spouse who does not need help with ADLs or (ii) a child within 10 miles as "with family support." ${ }^{3}$ Panel B of Table 1 tabulates the LTC demand patterns by family status, conditional on being under ADLH. ${ }^{4}$ The choice of the type of care used strongly depends on the availability of family support. For those who do have family support, about one-third of them choose to use HCBC, while more than half of those without family support enter a nursing home. The average number of care hours is larger with family support, which is particularly driven by the distribution's fat right tail. For those without family support, the distribution is bunched at 2,000 hours, which is the imputed value for nursing-home care.

\footnotetext{
${ }^{3}$ We found that having a child but not within 10 miles does not have much impact on LTC demand patterns.

${ }^{4}$ We focus on the demand conditional on ADLH from this point, as there is not much variation in the care type used under ADLL as Panel A shows. We do, however, make sure that the demand patterns from our model match the empirical patterns conditional on ADLL as well.
} 


\section{Table 1: LTC demand over health and family status}

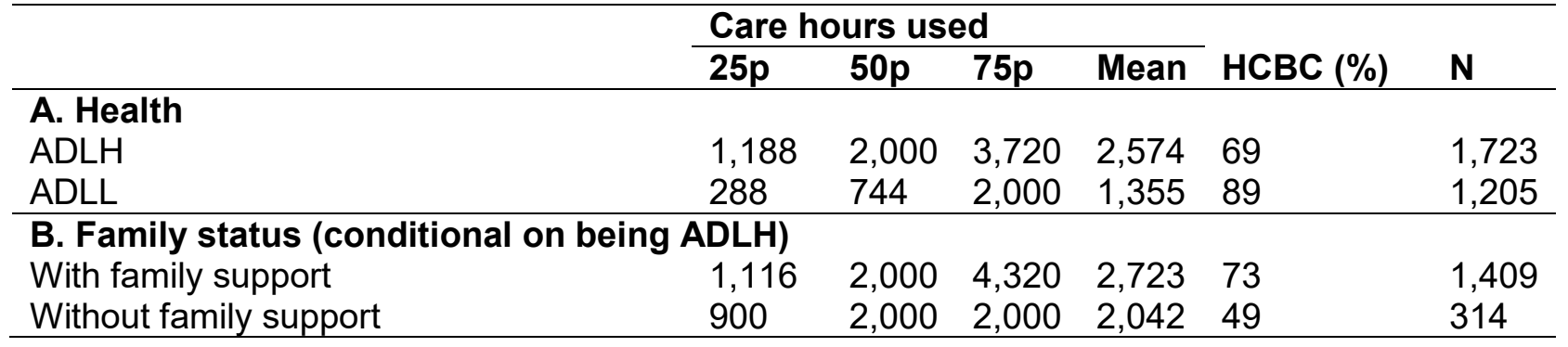

Note: Hours is the number of care hours received per year. Being in a nursing home is coded as 2,000 hours per year. Individuals who have a living spouse who does not need help with ADLs or have a child within 10 miles is considered to have family support.

Financial resources also affect the LTC demand patterns though their effect is smaller than that of family support. Table 2 shows the share of those using HCBC and the mean number of care hours received, conditional on income and wealth quartiles, family support, and being under ADLH. The impact of financial resources is more noticeable on the care type used (Panel A), where the share of HCBC has an inverted U-shape over income and wealth. The pattern is noisier for the number of hours. It should be noted that the small number of observations after conditioning on wealth and income quartiles - in particular, for those without family support - make the means more sensitive to outliers.

In the model we develop, we try to capture the key patterns presented. A much higher share of $\mathrm{HCBC}$ among those with family support means that the effective cost of using $\mathrm{HCBC}$ is much lower for them. This mostly reflects informal care provided by the family members. In our model, individuals without family support face a trade-off between the flexibility of $\mathrm{HCBC}$ and the cheaper cost of care (per hour) received at a nursing home. The inverted U-shape of the share of $\mathrm{HCBC}$ over financial resources will be generated as an outcome of this trade-off. 
Table 2: LTC demand over wealth and income

\begin{tabular}{|c|c|c|c|c|c|c|c|c|}
\hline \multirow{2}{*}{$\begin{array}{l}\text { A. HCBC (\%) } \\
\text { Family structure }\end{array}$} & \multicolumn{4}{|c|}{ Wealth quartiles } & \multicolumn{4}{|c|}{ Income quartiles } \\
\hline & $1 s t$ & 2nd & 3rd & 4th & 1st & 2nd & 3rd & 4th \\
\hline Without family support & 35 & 66 & 74 & 55 & 47 & 50 & 52 & 49 \\
\hline With family support & 67 & 76 & 82 & 79 & 74 & 72 & 73 & 77 \\
\hline B. Hours (Mean) & \multicolumn{4}{|c|}{ Wealth quartiles } & \multicolumn{4}{|c|}{ Income quartiles } \\
\hline Family structure & $1 \mathrm{st}$ & 2nd & 3rd & 4th & $1 \mathrm{st}$ & 2nd & $3 r d$ & 4th \\
\hline Without family support & 2,019 & 2,168 & 2,389 & 1,704 & 2,122 & 2,121 & 1,700 & 2,149 \\
\hline With family support & 2,808 & 2,649 & 2,884 & 2,420 & 2,914 & 2,531 & 2,594 & 2,874 \\
\hline
\end{tabular}

Note: This table tabulates the demand patterns conditional on being under ADLH. N=314 for those without family support; $\mathrm{N}=1,409$ for those with family support. Also see notes for Table 1.

\subsection{Supply}

To obtain basic facts regarding local competitions in the nursing home market, we use the Pennsylvania Department of Health's Nursing Home Reports, which cover the universe of nursing homes in Pennsylvania. ${ }^{5}$ We also use some moments reported in Hackmann (2019) that are also from the nursing homes in Pennsylvania.

Hackmann (2019) reports that $90 \%$ of nursing home entrants travel less than 15 miles/23 kilometers to find a nursing home. Based on this, we set the size of one nursing home market to be 700 square miles, the size of a circle with a radius of 15 miles. According to the Nursing Home Reports data, there are, on average, 11 nursing homes per each nursing home market. Using census data, we also find that there are 24,000 people 70 or older per nursing home market. Our quantitative model represents one nursing home market, and hence we calibrate the number of nursing homes and the size of the elderly population to match these facts. There are 90,000 beds in total in all 700 nursing homes in Pennsylvania, so on average, each nursing home has about

\footnotetext{
${ }^{5}$ We use the data from 2017 . The data can be accessed through the following link: https://www.health.pa.gov/topics/HealthStatistics/HealthFacilities/NursingHomeReports/Pages/ nursing-home-reports.aspx.
} 
130 beds. This number is not explicitly targeted in our model, but we check that the average size of nursing homes in our model matches this number.

According to the Nursing Home Reports, the average out-of-pocket costs of using a nursing home's semi-private room is about $\$ 85,000$ per year. ${ }^{6}$ Note that a nursing home provides not only health and personal care but also other amenities, including a room, food, cleaning service, etc. ${ }^{7}$ Considering this, and also that the perhour cost of intensive HCBC is about $\$ 35$ (Mommaerts 2016), a nursing home is a cheaper option for those who demand intensive long-term care but do not have family support, as they also need to outsource basic home production. ${ }^{8}$ This reflects that nursing homes can provide intensive care at a lower unit cost compared to HCBC, which is made possible by the nursing home's institutional setup and care standardization. Our model captures this feature as increasing returns to scale over the intensity of care in the nursing home cost function.

Hackmann (2019) documents that the Medicaid reimbursement rate is about $\$ 76,500$, which is $10 \%$ lower than the out-of-pocket price from the Nursing Home Reports. He also reports that a nursing home's average fixed operational cost is about $\$ 1.3$ million per year. Our quantitative model will generate the observed out-of-pocket price as the optimal price chosen by nursing homes facing the documented Medicaid reimbursement rate. Each nursing home in our model will have profits enough to cover

\footnotetext{
${ }^{6}$ This paper uses 2017 dollars.

${ }^{7}$ Hackmann (2019) reports that the nonhealth-related resident cost is about one-third of the health-related cost.

${ }^{8}$ See Section 5 for more details of the cost comparisons across different LTC options.
} 
the fixed operational costs but not too much to allow for a profitable entry of an additional nursing home.

\section{A static model of the long-term care market}

In this section, we propose a simple model of nursing home market, featuring optimizing consumers and producers, with a purpose of establishing intuition for the large quantitative model presented in the next section. Starting with the demand side, we characterize the demands for nursing home care: The private demand and the demand of Medicaid enrollees' (hereafter "Medicaid nursing home demand"). Then we examine the nursing home decisions given the care demands, and highlight the role of Medicaid in the incentives on both sides of the market.

Consider a closed community of individuals who need long-term care. They can obtain this care either at home ( $\mathrm{HCBC})$ or by moving to a nursing home. The two types of care differ in flexibility and prices, taken as given by an individual. While the intensity of care received at home is flexible and decided by an individual, a nursing home provides a uniform intensity to all residents. Individuals in a community are heterogeneous in wealth and the effective HCBC price. The latter is intended to capture the availability of informal care by family members.

There is a single nursing home operated by a monopolist. The monopolist observes the distribution of individuals and their Medicaid eligibility, and perfectly predicts the aggregate demand when deciding the price and care intensity. 


\subsection{The demand side}

Individual preferences are defined over consumption of care services $q^{k}$ of type $k \in\{H, N\}$ and noncare goods $c$ :

$$
U^{k}=u\left(q^{k}\right)+v(c),
$$

where $u($.$) and v($.$) are increasing, continuous, twice continuously differentiable, and$ concave. For expositional purposes in this section, we assume that preferences are also homothetic. Individual resources consist of wealth $\omega$ and government transfers $T R^{k}$ for care $k$, which are allocated between expenditures on care, $L T C^{k}$, and noncare goods:

$$
L T C^{k}+c=\omega+T R^{k} .
$$

The cost of $q$ hours of $\mathrm{HCBC}$ at a price $\rho$ per hour is $L T C^{H}=\rho q$, and the cost of a nursing home stay, which comes with fixed intensity $Q$, is $L T C^{N}=P$.

We first examine the care decision in the absence of public assistance for longterm care $\left(T R^{k}=0, \forall k\right)$. The optimal intensity of out-of-pocket HCBC, $q$, satisfies the first-order condition:

$$
u^{\prime}(q)=\rho v^{\prime}(\omega-\rho q) .
$$

Utility attained under HCBC determines the reservation utility for a potential nursing home entrant:

$$
U^{H}(\omega, \rho) \equiv u(q)+v(\omega-\rho q) .
$$

Both the optimal out-of-pocket $\mathrm{HCBC}$ and the reservation utility are increasing in wealth and declining in the price of $\mathrm{HCBC}$. 


\subsubsection{Private demand for nursing home care}

Taking as given nursing home care intensity, $Q$, and bed price, $P$, an individual chooses nursing home care if the utility attained in a nursing home exceeds her reservation utility:

$$
U^{N}(\omega, P, Q)=u(Q)+v(\omega-P) \geq U^{H}(\omega, \rho)
$$

For each individual wealth level $\omega$, the participation constraint (Equation 3) determines the reservation level of nursing home intensity $Q(\omega, P, \rho)$, such that for $Q>$ $\mathcal{Q}(\omega, P, \rho)$ the individual strictly prefers nursing home, and for $Q<\mathcal{Q}(\omega, P, \rho)$ they prefer HCBC. The marginal individuals - those with binding participation constraints, $Q=$ $\mathcal{Q}(\omega, P, \rho)$ - determine the demand schedule faced by the nursing home. Hence the properties of the demand for nursing home care can be derived from the properties of the reservation intensity function.

Proposition 1

The reservation intensity $\mathcal{Q}(\omega, P, \rho)$ is U-shaped in wealth, increasing in the price of the nursing home and declining in the price of $\mathrm{HCBC} .^{9}$

Our quantitative model will distinguish between two types of individuals, with and without family support, to capture the fact that households with able spouses and/or a child nearby face a lower price of $\mathrm{HCBC}$ compared to a single individual without a child living nearby: $\rho_{F}<\rho_{S}$. Figure 1 a considers two such individuals, whose optimal HCBC allocations are indicated by points $S$ and $F$. The indifference curves passing through those points correspond to their participation constraints (Equation 3). Any nursing

${ }^{9}$ For the proofs of the propositions in this paper, please see the Online Appendix at https://sites.google.com/site/minjoonlee/research/MRDRC_AppendixB.pdf. 
home intensity-price combination that delivers a point above the indifference curve is accepted. A nursing home charging price $P$ would have to deliver at least $Q_{S}$ for the single individual, and at least $Q_{F}$ for the one with family. A nursing home with an intensity-price offer associated with point $N$ is accepted by the single individual, but not by the individual with family.

\section{Figure 1: Extensive margins of demand}

(a) HCBC-price margin

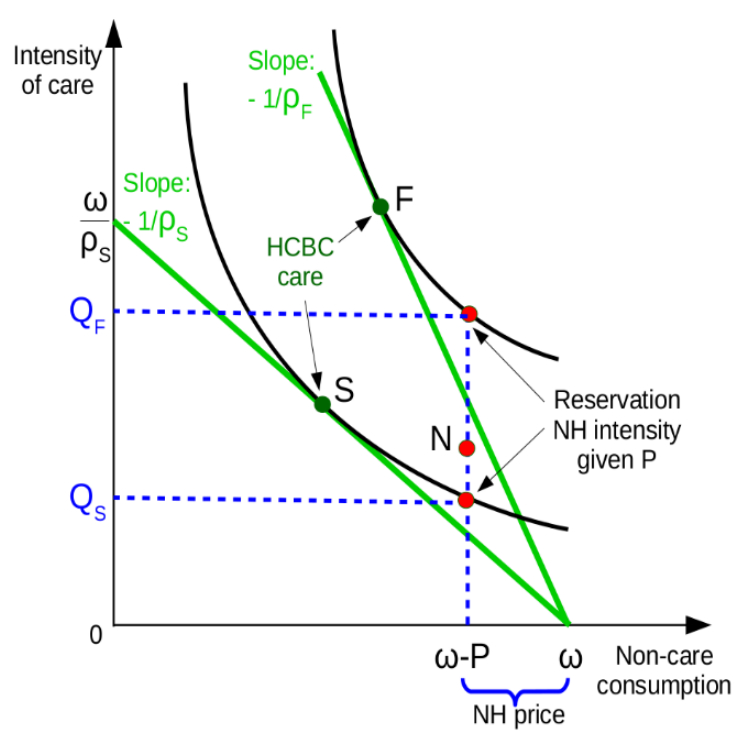

(b) Wealth margin

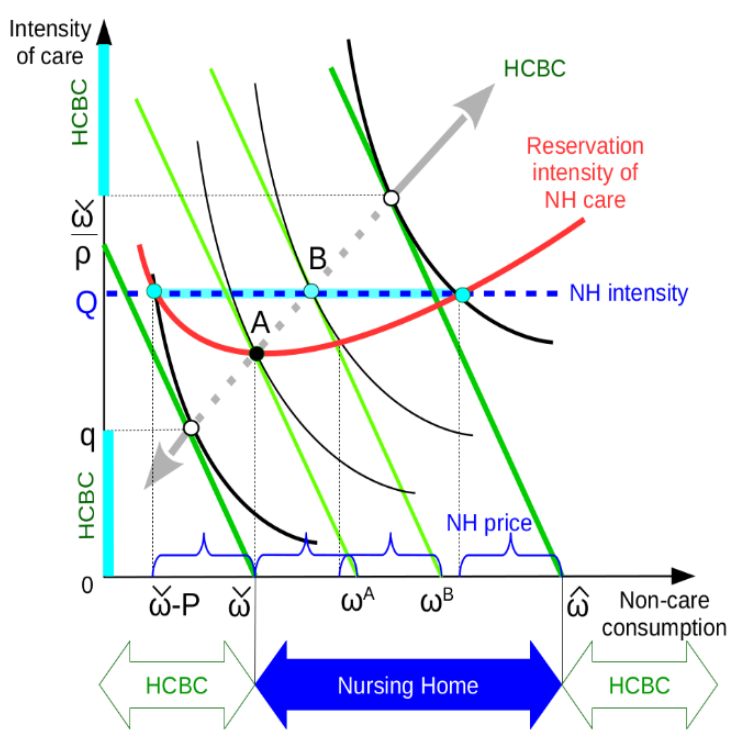

Figure $1 \mathrm{~b}$ illustrates how the reservation intensity of nursing home care changes with wealth level given nursing home price $P$ and intensity $Q$ in a community of individuals facing the same HCBC price (e.g., single individuals without family support). Each point of the reservation intensity curve is found similarly to Figure 1a: For each level of wealth $\omega$, locate a point with noncare consumption $(\omega-P)$ on the HCBC indifference curve (the participation constraint). For the marginal individuals - those with wealth levels $\breve{\omega}(P, Q \mid \rho)$ and $\widehat{\omega}(P, Q \mid \rho)$ - the participation constraint is binding: $Q=$ 
$\mathcal{Q}(\breve{\omega}, P, \rho)=\mathcal{Q}(\widehat{\omega}, P, \rho)$. Individuals with $\omega \in(\breve{\omega}, \widehat{\omega})$ are strictly better off at the nursing home. The reservation intensity for an individual with wealth level $\omega^{A}$ is equal to his optimal HCBC intensity, which also corresponds to the minimum of the reservation intensities across the wealth distribution, given care prices $P$ and $\rho$. Homothetic preferences imply that the minimum of all acceptable intensity levels equalizes the unit price of care: $\mathcal{Q}\left(\omega^{A}, P, \rho\right)=q=\frac{P}{\rho}$. Notice that nursing home intensity exceeds the optimal HCBC intensity for individuals with wealth below $\omega^{B}$, and is below the optimal HCBC intensity for wealthier individuals.

The reservation intensity curve makes it clear how the pool of nursing home residents changes as a nursing home varies its intensity: Higher intensity attracts more residents at both ends of the wealth spectrum. HCBC is used by poorer individuals, who cannot afford the nursing home and have make do with little care, and by richer individuals, who demand higher care intensity.

Let the distribution of individuals be continuous over the support $\omega \in[\underline{\omega}, \bar{\omega}]$ with cdf $\Phi_{i}(\omega)$ and a continuous positive pdf $\phi_{i}(\omega), i \in\{S, F\}$. Let $\psi_{i}$ be the share of individuals with $\mathrm{HCBC}$ price $\rho_{i}$. Given these assumptions and Proposition 1, the following proposition formally states the private demand for nursing home and characterizes its properties.

Proposition 2

The private demand for nursing home care by individuals of type $i \in\{S, F\}$ can be written as follows:

$$
n_{i}(P, Q)=\psi_{i}\left[\Phi_{i}\left(\widehat{\omega}_{i}\right)-\Phi_{i}\left(\breve{\omega}_{i}\right)\right]
$$


where wealth levels of the marginal individuals, $\left\{\widehat{\omega}_{i}, \breve{\omega}_{i}\right\}$, solve Equation 3 at equality for each $\left(P, Q, \rho_{i}\right)$, such that $\breve{\omega}_{i} \leq \widehat{\omega}_{i}$. The demand has standard properties: it decreases in price, and increases in intensity and the price of HCBC: $\frac{\partial n_{i}}{\partial P}<0, \frac{\partial n_{i}}{\partial Q}>0$, and $\frac{\partial n_{i}}{\partial \rho_{i}}>0$.

Figure 2a shows the allocation of care in the space of wealth and the HCBC price. Nursing home is never chosen by individuals whose price of HCBC is below the unit price of nursing home care, $\rho<\frac{P}{Q} .{ }^{10}$

Figure 2. Allocation of care given the price and intensity of nursing homes

(a) No Medicaid

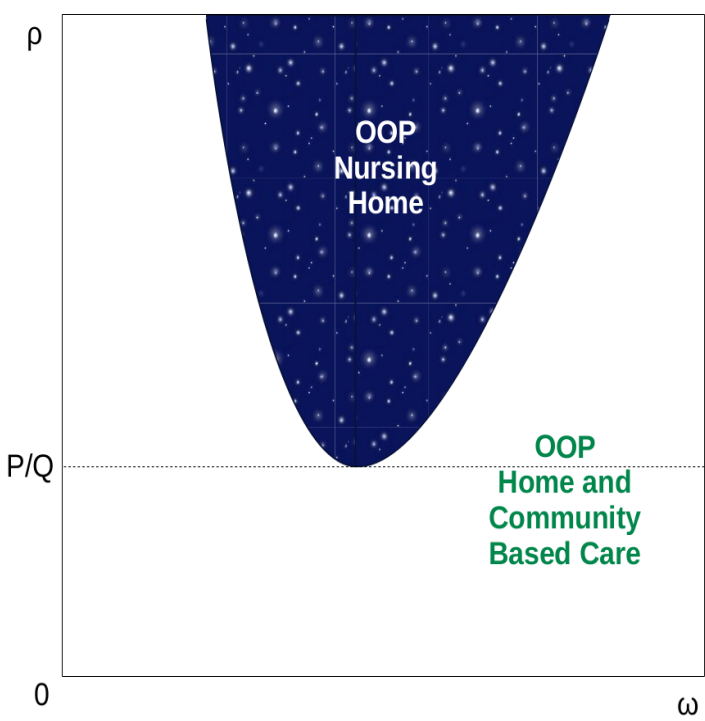

(b) With Medicaid

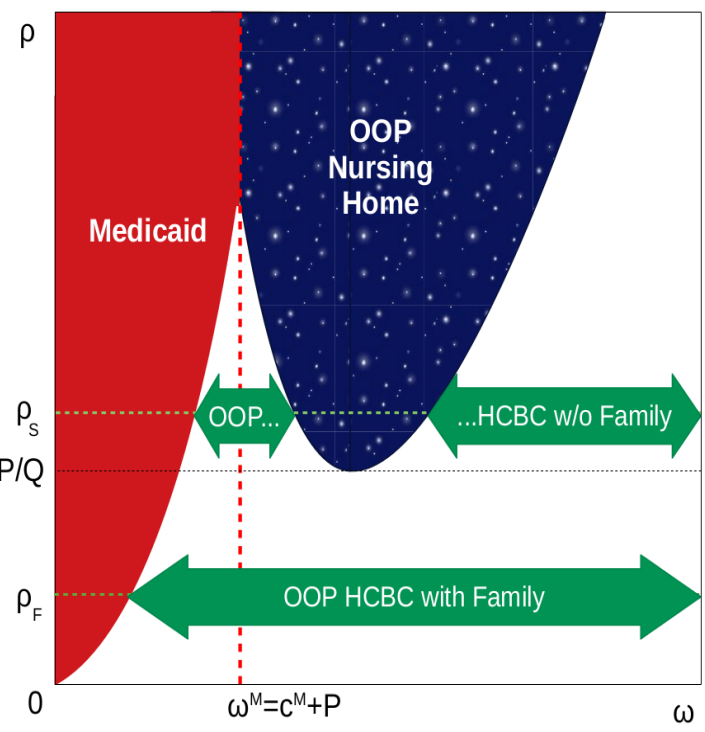

\section{$\underline{\text { 3.1.2 Nursing home demand with Medicaid }}$}

Consider a Medicaid LTSS policy that pays for a nursing home of given intensity $Q$ and provides individual with consumption floor $c^{M} .{ }^{11}$ We assume that the policy pays

\footnotetext{
${ }^{10}$ In the quantitative model, we allow for preference shocks that introduce a random component to the choice of care so that some individuals with low price of HCBC prefer nursing home care.
} 
for the same amount of HCBC. For expositional purposes, we also assume the same consumption floor provided by Medicaid in the HCBC setting, making a Medicaid enrollee indifferent between a nursing home and HCBC. Without loss of generality, here we allocate those individuals to nursing home care.

To enroll in Medicaid LTSS program, an individual must require long-term care and his resources must be insufficient to achieve the consumption floor on his own conditional on receiving nursing home care. To receive Medicaid transfers, all individual wealth must be forfeited.

An individual chooses among three options: $\operatorname{HCBC}(k=H)$, out-of-pocket nursing home care $(k=N)$, and Medicaid nursing home $(k=M)$ :

$$
\max \left\{U^{H}(\omega, \rho), U^{N}(\omega, P, Q), U^{M}\left(c^{M}, Q\right)\right\},
$$

where $U^{M}\left(c^{M}, Q\right)=u(Q)+v\left(c^{M}\right)$.

Conditional of using a nursing home, the choice between Medicaid and OOP option is trivial: Medicaid is preferred if $\omega<c^{M}+P$. Among individuals who would choose $\mathrm{HCBC}$ in the absence of Medicaid, being a Medicaid nursing home resident is preferred by those with high $\mathrm{HCBC}$ price relative to individual resources. That is, not all individuals eligible for Medicaid choose Medicaid nursing home. Figure 3a shows the indifference curve corresponding to the utility delivered by the Medicaid stay at the nursing home. The points on the indifference curve correspond to marginal individuals

\footnotetext{
11 This set up differs from the quantitative model featuring fixed consumption value of nursing home. The discrepancy is due to the static versus dynamic setup and for the ease of exposition: In the static model, we abstract from the consumption value of nursing home and interpret private residents' consumption as capturing the bequest value of their wealth. To be able to examine effects of Medicaid generosity in the static model, $c^{M}$ has to be one of the Medicaid policy parameters.
} 
characterized by the combination of their resources and $\mathrm{HCBC}$ price, $(\omega, \rho)$. Consider the steepest budget constraint (the lowest $\mathrm{HCBC}$ price): Individuals with wealth below $\omega$ strictly prefer a Medicaid stay at the nursing home to $\mathrm{HCBC}$. As the $\mathrm{HCBC}$ price increases, wealthier individuals switch from $\mathrm{HCBC}$ to Medicaid nursing home stay. Formal derivation of the Medicaid-HCBC frontier - a locus of points $(\omega, \rho)$ such that $U^{H}(\omega, \rho)=U^{M}\left(c^{M}, Q\right)-$ is provided in the Appendix and its properties are illustrated below.

Figure $2 \mathrm{~b}$ shows the care allocation in the HCBC price-wealth space, given the intensity and price of nursing home, as well as the consumption value of Medicaid nursing home. Consider two levels of HCBC prices: $\rho_{F}<P / Q$ (with family) and $\rho_{S}>$ $P / Q$ (single, without family). For singles, poor individuals rely on Medicaid, middleincome individuals choose OOP nursing home, and the rest use HCBC. For individuals with family, poor use Medicaid nursing home and the rest use relatively cheap HCBC. For the rest of this subsection, we focus on these two types of individuals, with wealth levels such that the marginal tradeoff is between the Medicaid nursing home and HCBC, i.e., $\omega<c^{M}+P$. 


\section{Figure 3: Choice between HCBC and Medicaid nursing home}

(a) Allocation given the intensity of nursing home care

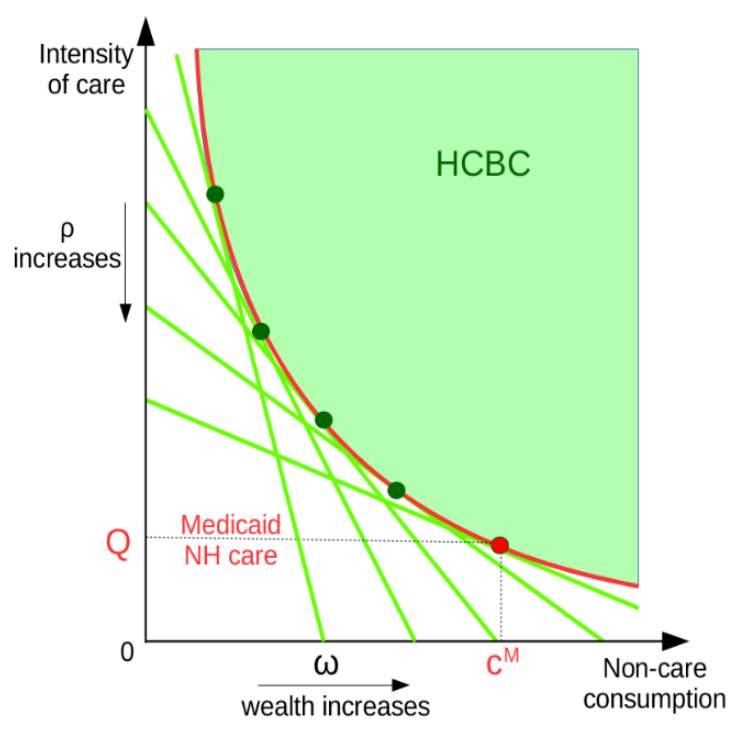

(b) Effects of increase in the intensity of nursing home care

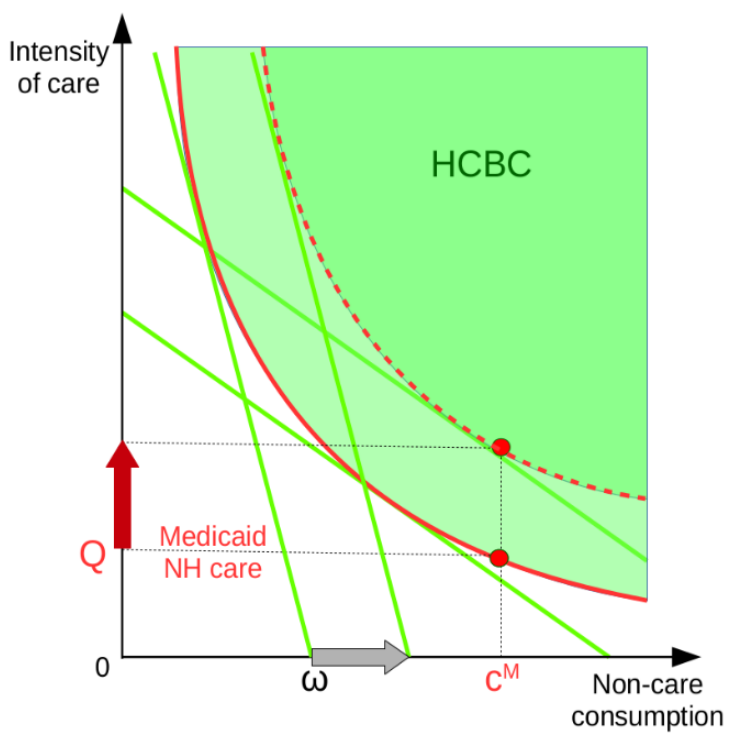

As the utility of a Medicaid nursing home stay increases, either due to higher care intensity or higher Medicaid consumption floor, the Medicaid option becomes attractive to individuals with more resources at each $\mathrm{HCBC}$ price level. Figure $3 \mathrm{~b}$ shows the increase in Medicaid nursing home demand for the case of higher intensity. At any given $\mathrm{HCBC}$ price, the wealth of individuals willing to switch to the Medicaid nursing home increases. Figure 4a shows the overall increase in demand for Medicaid nursing home due to higher consumption floor. Increasing nursing home care intensity has a qualitatively similar effect on the choice between Medicaid nursing home versus HCBC (Figure 4b). However, as discussed in Section 3.1.1, higher nursing home intensity also expands the pool of out-of-pocket residents as individuals switch from $\mathrm{HCBC}$ to out-ofpocket nursing home on both side of the wealth spectrum. Finally, an increase in the nursing home bed price has the opposite effect on the private demand for nursing home, but has no effect on the Medicaid-HCBC frontier (Figure 4c). 
Figure 4: Effects of changes in Medicaid eligibility, Medicaid consumption, and price of nursing home on the demand for care

(a) More generous Medicaid (increase in $c^{M}$ )

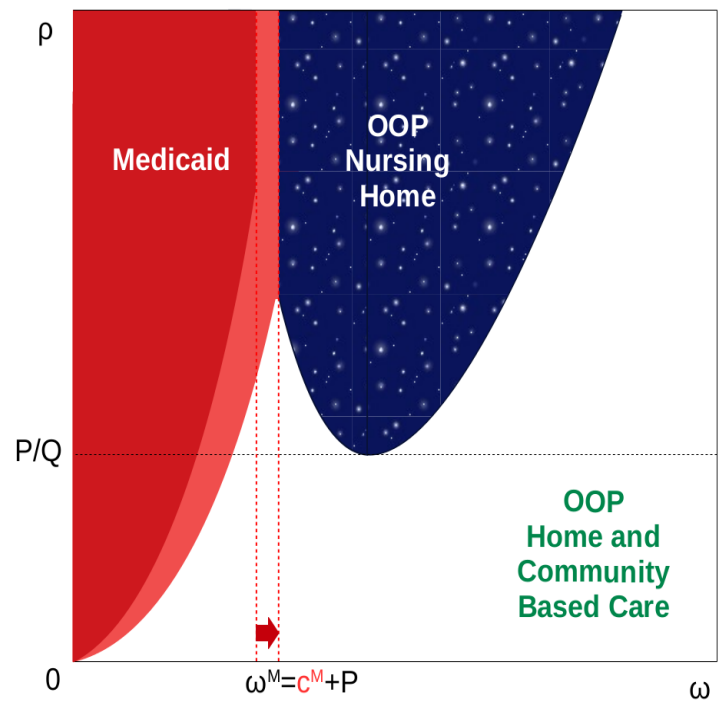

(b) Higher intensity of nursing home (Q)

(c) Higher price of nursing home $(P)$
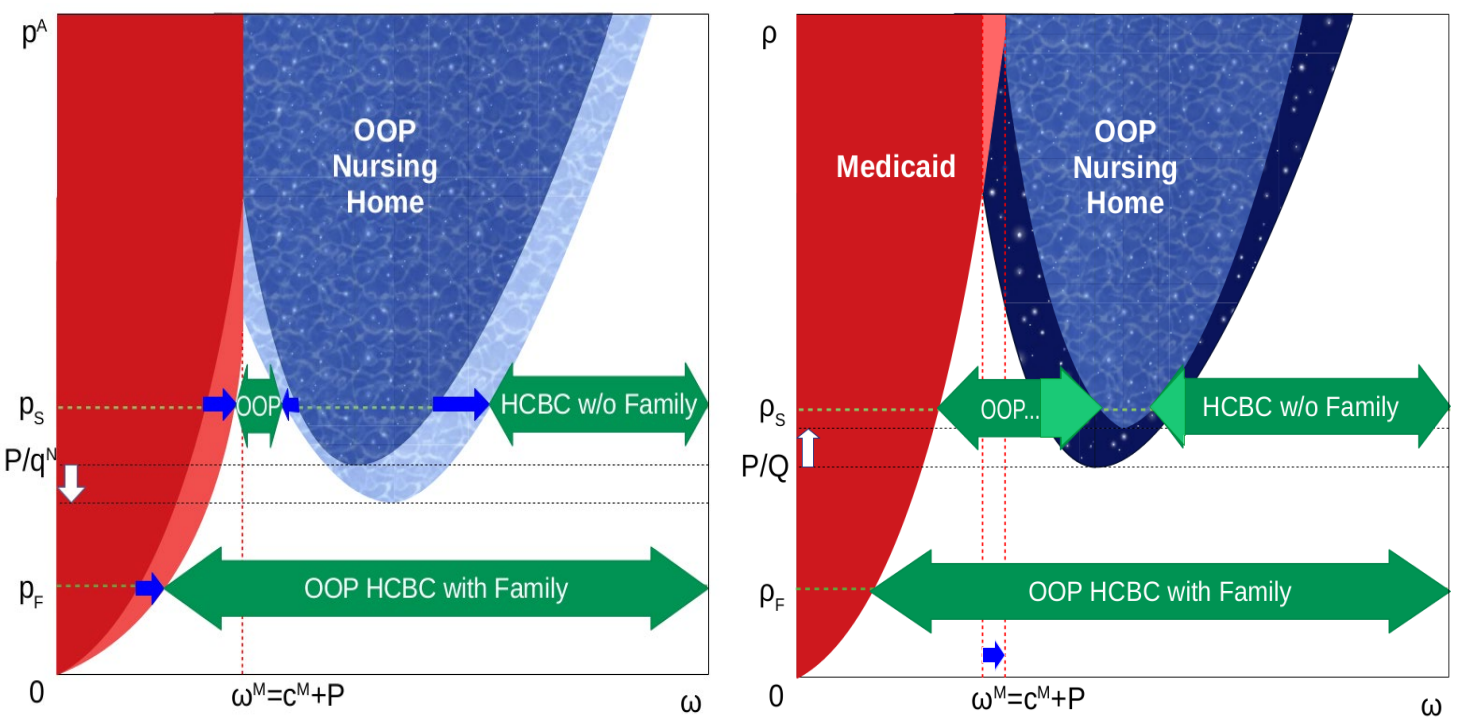
Given the assumptions on the distribution of agents made in Section 3.1.1, the following propositions formally state the Medicaid demand and summarize its properties.

\section{Proposition 3}

The Medicaid demand for nursing home by individuals of type $i \in\{F, S\}$ can be stated as

$$
m_{i}\left(Q \mid c^{M}\right)=\psi_{i} \Phi_{i}\left[\omega^{M}\left(Q \mid c^{M}, \rho_{i}\right)\right],
$$

where $\omega^{M}\left(Q \mid c^{M}, \rho_{i}\right)<C^{M}+P$ is the wealth of the marginal individual of type $i$ who is indifferent between out-of-pocket $\mathrm{HCBC}$ and Medicaid nursing home, with $\omega^{M}\left(Q \mid c^{M}, \rho_{F}\right)<\omega^{M}\left(Q \mid c^{M}, \rho_{S}\right)$.

\section{Proposition 4}

Let $q_{i}$ be the optimal HCBC intensity of individual of type $i \in\{F, S\}$, with wealth $\omega_{i}^{M}$ such that $U^{H}\left(\omega_{i}^{M}, \rho_{i}\right)=U^{M}\left(c^{M}, Q\right)$. The Medicaid demand of individuals of type $i \in$ $\{F, S\}$ has the following properties:

The slope of the demand over intensity is positive:

$$
\frac{\partial m_{i}}{\partial Q}=\psi_{i} \phi_{i}\left(\omega_{i}^{M}\right) \frac{u^{\prime}(Q)}{v^{\prime}\left(\omega_{i}^{M}-\rho_{i} q_{i}\right)} \geq 0 .
$$

The demand is increasing in the Medicaid generosity (consumption floor):

$$
\frac{\partial m_{i}}{\partial c^{M}}=\psi_{i} \phi_{i}\left(\omega_{i}^{M}\right) \frac{v^{\prime}\left(c^{M}\right)}{v^{\prime}\left(\omega^{M}-\rho_{i} q_{i}\right)}>0 .
$$

The slope of the Medicaid demand over intensity increases with the Medicaid generosity if either the density margin is non-negative or the preference margin dominates a negative density margin: 


$$
\frac{\partial^{2} m_{i}}{\partial Q \partial c^{M}}=\frac{\psi_{i} u^{\prime}(Q) v^{\prime}\left(c^{M}\right)}{\left[v^{\prime}\left(\omega_{i}^{M}-\rho_{i} q_{i}\right)\right]^{2}}\left[\phi_{i}^{\prime}\left(\omega_{i}^{M}\right) \underset{\text { density }}{\omega_{\text {preferences }}^{-\phi\left(\omega_{i}^{M}\right)} \underbrace{v^{\prime \prime}\left(\omega^{M}-\rho q_{i}\right)}_{v^{\prime}\left(\omega_{i}^{M}-\rho q_{i}\right)}}\right] .
$$

To sum up, the aggregate demand for nursing home care consists of private payers' demand and Medicaid enrollees' demand. Private payers are individuals in the middle range of the wealth distribution, for whom nursing home care intensity is close to what they would have chosen under out-of-pocket HCBC. Medicaid allows poor individuals, who are priced out of nursing home care, to achieve higher levels of care relative to out-of-pocket HCBC. While the number of private residents can be controlled with both price and intensity of nursing home care, Medicaid demand only responds to the latter.

\subsection{The supply side}

\subsubsection{Nursing home problem}

We now consider the decisions of a monopolistic nursing home that takes as given the demand for beds studied above. The nursing home chooses price and care intensity. We assume that care intensity is a public good: The nursing home cannot discriminate among the residents on intensity. We also rule out price discrimination. Although the nursing home cannot deny a bed to a Medicaid resident, it can still control the Medicaid demand for its beds by varying the care intensity. The nursing home takes as given the reimbursement rate, $M<P$, set and paid by Medicaid, In this sense, it acts as a partial price-taker. ${ }^{12}$

\footnotetext{
12 If servicing all qualifying residents implies negative profits, the nursing home does not operate.
} 
The nursing home faces the cost schedule $C(N, Q)$, where $N=n+m$ is the total number of beds, with the following properties: The marginal cost of bed $C_{N}$ is increasing in the number of beds and intensity $\left(C_{N N}>0, C_{N Q}>0\right)$, and the marginal cost of a unit of intensity (an hour of care) is nonincreasing in the total intensity $\left(C_{Q Q} \leq 0\right)$. These assumptions are consistent with nursing home capacity constraints and potential increasing returns to scale in intensity due to centralized care provision. ${ }^{13}$

The nursing home chooses price and intensity taking as given aggregate private demand $n(P, Q) \equiv \sum_{i=S, F} n_{i}\left(P, Q \mid \rho_{i}\right)$ and aggregate Medicaid demand $m\left(Q \mid c^{M}\right)=\sum_{i=S, F}$ $m_{i}\left(Q \mid c^{M}, \rho_{i}\right):$

$$
\max _{P, Q} \operatorname{Mm}\left(Q \mid c^{M}\right)+P n(P, Q)-C(n(P, Q)+m(Q), Q) .
$$

The first-order conditions for price and intensity are:

$$
\begin{aligned}
-\left(P-C_{N}\right) \frac{\partial n}{\partial P} & =n(P, Q), \\
\left(M-C_{N}\right) \frac{\partial m}{\partial Q}+\left(P-C_{N}\right) \frac{\partial n}{\partial Q} & =C_{Q} .
\end{aligned}
$$

The terms in parentheses correspond to profit margins: $\left(P-C_{N}\right)$ is the marginal profit on a private bed and $\left(M-C_{N}\right)$ is the marginal profit on a Medicaid bed, which we assume to be positive. Equation 11 ensures that, at the optimum, the benefit of increasing price by $\$ 1$ on each of $n$ private residents (the right-hand side) equals the profit loss due to residents forgoing nursing home in favor of relatively cheaper HCBC (the left-hand-side). Equation 12 weighs the cost of increasing intensity by 1 hour (the right-hand side) against the benefits: marginal profits generated by the additional

\footnotetext{
${ }^{13}$ These assumptions are consistent with the results of our calibration procedure for the quantitative model, which does not preimpose these conditions (see Section 5).
} 
demand for nursing home care (the left-hand-side) from both private and Medicaid residents attracted by higher intensity. ${ }^{14}$

\subsubsection{The role of Medicaid}

One of this paper's main goals is to understand how Medicaid affects the nursing home market: care intensity, bed price, number of beds, distribution of residents, and overall welfare. Although assessing many of these effects requires a quantitative analysis, this section highlights the channels underlying the nursing home incentives, as well as identifies unambiguous effects whenever possible.

In our analysis, two policy variables characterize Medicaid: the reimbursement rate $M$ on the supply side and the consumption floor $c^{M}$ on the demand side. Moreover, Medicaid enforces a rule which does not allow a nursing home to reject an eligible resident.

Suppose there exists a market equilibrium where a nursing home makes positive profits given Medicaid policy $\left(M, c^{M}\right)$. Now consider a more generous Medicaid policy first on the supply side, then on the demand side.

Medicaid generosity on the supply side

Consider an increase in the Medicaid reimbursement rate $M$. The policy change directly increases the profit margin on Medicaid bed on the left-hand-side of Equation 12. Higher return on Medicaid beds induces nursing home to supply higher care intensity in order to attract more Medicaid residents. Higher intensity also increases the private demand. Decreasing returns to the bed numbers imply that higher number of

\footnotetext{
${ }^{14}$ Without Medicaid residents, the solution to the monopolist problem is standard and may feature under- or oversupply of intensity relative to the competitive outcome, depending on the private demand elasticities with respect to intensity.
} 
residents, together with higher intensity, raises the marginal cost of bed, $C_{N}(n+m, Q)$, and reduces profit margins on both types of beds. Holding the slope of the private demand, $\frac{\partial n}{\partial P}$, constant, lower profit margin on a private bed reduces the marginal cost of raising the bed price (the left-hand-side of Equation 11), while larger numbers of private payers increases return to raising the price (the right-hand-side of Equation 11). However, whether the price increases depends on how the slopes of the demand responds to higher intensity, i.e., on the sign of $\frac{\partial^{2} n}{\partial P \partial Q}$. Furthermore, increasing returns to scale in intensity reduce the marginal costs of extra care hour, further raising care intensity. While it is unambiguous that both the number of Medicaid beds and care intensity increase, the effects on the number and price of private beds are ambiguous. Both nursing homes and their Medicaid residents stand to benefit from the higher reimbursement rate while the private LTC consumer may be disadvantaged.

Medicaid generosity on demand side

Now consider an increase in the consumption floor for Medicaid nursing home residents, $c^{M}$. Proposition 4(Equation 8 ) states that higher consumption floor stimulates the demand for nursing home care and increases the number of residents, holding all else constant. This inflow of Medicaid residents has a direct impact on the marginal cost of bed, $C_{N}$, and of an extra care hour, $C_{Q}$, which reduce the profit margins on both types of beds and reduce incentives to provide higher intensity. At the same time, there are two channels that promote higher intensity: higher demand elasticities with respect to intensity and lower marginal cost of intensity. The former property has been discussed in Proposition 4 (Equation 9): A higher consumption floor amplifies the response of the Medicaid demand to intensity provided the loss on the density margin is small or non- 
negative. The latter channel arises due to the assumption of increasing returns to scale in intensity. In the end, the effect on intensity is ambiguous. On the other hand, the price unambiguously increases and the number of private beds falls as the cost of raising the price on private beds declines. To sum up, more generous policy on the demand side crowds out private beds with Medicaid beds and increases the bed price, while its effect on intensity and nursing home profits is ambiguous.

Thus, Medicaid generosity targeted at either demand or supply side affects both sides of the nursing home market. Both policies increase the share of Medicaid beds and, hence, increase Medicaid outlays. Higher Medicaid reimbursement rates directly benefit nursing homes with some of the benefits being passed on to the existing and new residents in terms of higher care intensity. A higher consumption floor directly benefits existing Medicaid nursing home residents, as well as those who switch from out-of-pocket $\mathrm{HCBC}$ to Medicaid nursing home in terms of consumption, but has ambiguous effects on care intensity used.

\section{Quantitative model}

Our quantitative model extends the stylized model in the following ways. On the household side, the optimization problem is dynamic. Households make saving decisions and value bequests. Households face stochastic health transitions and mortality risk as they get older. They also face preference shocks that capture the role of the factors not explicitly captured in our modeling of LTC choice (e.g., distance of a nursing home from their family). On the supply side, we explicitly capture the local competition among nursing homes and allow for a rich cost structure. 


\section{1 Households}

Households in our model are heterogeneous in their age, wealth, income, family structure, and health. We first describe the choices households make in each period given this state. Then we present the full dynamic problem by explaining how the state evolves over time.

\subsubsection{Optimization problem in each period}

State variables: In each period, the following state variables summarize a household's current status:

1. Age $(t)$ : For simplicity, for couples, we assume that they have the same age.

2. Family situation $\left(F_{t}\right)$ : This captures the following information: (i) whether the male and female spouses are alive or not; (ii) whether the household has a living child or not; (iii) if there is a living child, whether the household has a child within 10 miles or not.

3. Wealth $\left(W_{t}\right)$ : The total value of wealth owned by the household. ${ }^{15}$

4. Income $\left(\mathbf{Y}_{t}=\left\{Y_{m, t}, Y_{f, t}\right\}\right)$ : This captures the retirement income from Social Security and defined-benefit pensions for the household's living members. It is a vector with two elements, capturing income of male $\left(Y_{m, t}\right)$ and female $\left(Y_{f, t}\right)$ separately.

5. Permanent income (PI): This captures the average earnings made while household members were working.

\footnotetext{
${ }^{15}$ For tractability, we do not distinguish housing and financial wealth.
} 
6. Health $\left(\mathbf{h}_{t}=\left\{h_{m, t}, h_{f, t}\right\}\right)$ : This captures the health status of the household's living members. Potential values it can take are good $(G)$, bad $(B)$, low need for help with the ADLs $(A D L L)$, and high need for help with the ADLs $(A D L H)$. Being Good and Bad has no difference in terms of the current demand for long-term care (which is zero), but it affects the health transition probabilities. ${ }^{16}$ It is a vector with two elements, capturing health of male $\left(h_{m, t}\right)$ and female $\left(h_{f, t}\right)$ separately.

In describing the household choice problem below, to simplify the notation, we drop the age subscript. The variables without a prime (') are the current-period variables, while the ones with a prime is the next-period variables.

Flow utility function: Households face the following flow utility function:

$$
U(\mathbf{c}, \mathbf{q}, \mathbf{k} ; \mathbf{h}, \xi, F) \equiv \sum_{g=m, f} 1_{g}\left[\theta_{g}^{h}\left(u\left(q_{g}^{k} ; h_{g}\right)+\xi_{g}^{k}\right)+v\left(c_{g}+\Delta_{g}^{k}\right)\right] .
$$

$1_{g}$ is the indicator function that takes the value of one if the member of the corresponding gender is alive, and zero otherwise. For couples, this is the sum of the utilities of two members. Each member's flow utility is composed of two terms: utility from LTC consumption (the first term inside the bracket) and that from noncare consumption (the second term).

Care consumption's relative importance of is governed by the utility multiplier, $\theta_{g}^{h}$. This parameter depends on the current health. In particular, it is zero when the health is $G$ or $B$ (because we do not explicitly model health care other than long-term care), while

\footnotetext{
${ }^{16}$ In mapping these categories to the HRS, Good is defined as not needing help with ADLs and the self-reported health status being excellent, very good, or good. Bad is defined as not needing help with ADLs and the self-reported health status being fair or poor.
} 
it takes positive values when the health is $A D L L$ or $A D L H . u$ is an increasing and concave function of the hours of care received $\left(q_{g}^{k}\right)$ and the superscript $k$ refers to the type of care chosen (see below). Note that we allow the health state to affect not only $\theta_{g}^{h}$ but also $u$, to capture the possibility that the subsistence level of long-term care may be different between $A D L L$ and $A D L H . \xi_{g}^{k}$ is a preference shock. Households draw one preference shock for each care option available. This preference shock allows households to take into account factors that are relevant for the care-type choice but not explicitly modeled (such as distance from family). Moreover, the preference shock allows us to handle local competition in the nursing home market in a simple and tractable way. The distributions are independent across care options and drawn from an exponential distribution with a variance of $\sigma_{\xi}^{2} .{ }^{17}$

The noncare utility function, $v$, is increasing and concave in the noncare consumption, $c_{g}+\Delta_{g}^{k}$, where $c_{g}$ is consumption of goods and services purchased and $\Delta_{g}^{k}$ is consumption value of staying in a nursing home if the considered member is in a nursing home (see below for the latter).

Care options: When a member's health is $A D L L$ or $A D L H$, households can choose to either enter a nursing home or use $\mathrm{HCBC} .{ }^{18}$ For each option, households can choose to pay out of pocket or to rely on Medicaid.

\footnotetext{
17 To make the choice between entering a nursing home and using $\mathrm{HCBC}$ unaffected by the number of nursing homes, in calculating the utility from using $\mathrm{HCBC}$, we draw preference shocks of the same number as the number of nursing homes and use the largest value. This guarantees that households use options that are equally attractive before the preference shocks with the same probabilities.

${ }^{18}$ In the case when both members' health statuses are $A D L L$ or $A D L H$, we do not allow them to choose different care options. Either both enter a nursing home or both use HCBC. This
} 
Nursing home $j \in\{1, \cdots, J\}$ provides $Q_{j}$ hours of care for both out-of-pocket $(k=$ $\left.N_{j}^{O}\right)$ and Medicaid $\left(k=N_{j}^{M}\right)$ patients. The out-of-pocket cost is $P_{j}$ per year. Staying in a nursing home as a private patient also comes with consumption value, $\Delta_{N}^{O}$ (assumed to be the same across nursing homes). Medicaid patients do not pay out of pocket for care, but they forfeit income and wealth above certain thresholds (see the explanations on the budget constraint and the transfers below). The consumption value of a Medicaid nursing home stay, $\Delta_{N}^{M}$, can be smaller than $\Delta_{N}^{O}$. This is to capture the possibility of public care aversion (Ameriks et al. 2011) and nursing homes providing fewer amenities to public patients.

The main benefit of using $\mathrm{HCBC}$ out of pocket $\left(k=H^{o}\right)$ is the flexibility in choosing the care hours based on one's needs and preferences. The cost per care hour is $\rho(F, \mathbf{h})$, so the total cost is $\rho(F, \mathbf{h}) q_{g}$, where $q_{g}$ is the hours of care demanded by the individual. Note that the unit price of care depends on the family structure and the health status. This allows for the possibility that the effective cost of using HCBC may be lower if they have a healthy spouse or a child living nearby. For single households, or for those with both spouses needing help with ADLs, they also need to pay for housekeeping services. We assume that those households need to pay additional fixed cost, $\Psi$, regardless of the number of care hours used.

For Medicaid-funded HCBC $\left(k=H^{M}\right)$, we assume that Medicaid pays up to some number of hours, $Q_{H}^{M}$. Because the out-of-pocket price is zero, individuals in the model always use the maximum allowed number of hours. Households using this option help with ADLs at the same time, it happens to about $1 \%$ of households older than 70 . 
face the same regulation regarding income and wealth to be kept as in the Medicaid nursing home option.

Budget constraint: Households face the following budget constraint:

$$
W^{\prime}=(1+r)\left(W+\sum_{g=m, f} \mathbf{1}_{g}\left[Y_{g}-c_{g}-\operatorname{LTC} C_{g}^{k}\left(q_{g}, \mathbf{h}, F\right)\right]+T R\right) .
$$

The budget constraint defines the evolution of the household beginning-of-period wealth $W$. It is accumulated with the retirement income net of expenditures and government transfers $(T R)$ associated with Medicaid LTSS programs. Expenditures include consumption of noncare goods and services and private care-service costs. The latter depends on the health as well as type and quantity of care received:

$$
\operatorname{LTC}_{g}^{k}\left(q_{g}, \mathbf{h}, F\right)= \begin{cases}P & \text { if } k=N_{j}^{O} \\ \rho(\mathbf{h}, F) q_{g}+\psi(\mathrm{h}, F) & \text { if } k=H^{O} \\ 0 & \text { if } k=N_{j}^{M}, k=H^{M}, \text { or } h_{g} \in\{B, G\} .\end{cases}
$$

The last case indicates that the LTC expenditure is zero when their health is Good or Bad, or if they become a Medicaid enrollee.

Transfers: The transfer term in the budget constraint (Equation 14) captures the role of Medicaid. The following rules determine the transfer value in all four potential cases:

- For households that do not receive care based on Medicaid, there is no transfer:

$$
T R=0 .
$$

- For households where all the members are Medicaid enrollees, Medicaid forfeits households' entire wealth and income. In addition, a Medicaid 
enrollee using $\mathrm{HCBC}$ receives a consumption transfer which guarantees a minimum of noncare consumption $\left(\Delta_{W}\right)$ :

$$
\left.T R=\sum_{g=m, f} \mathbf{1}_{g}\left[\Delta_{W} \mathbf{I}^{k_{g}=H^{M}}-Y_{g}\right]-W\right] .
$$

- For coupled households where one member $(g=i)$ is Medicaid LTSS enrollee and the other member $(g=j)$ does not require long-term care, households forfeit part of their wealth and income according to the following rule. For the income, the healthy spouse can keep the larger value between her/his income and a certain lower bound set to prevent impoverishment of the healthy spouse $(\underline{Y})$. For wealth, the household can keep the full amount of its assets up to the threshold $\underline{W}$, and $50 \%$ of wealth above $\underline{W}$. The amount of wealth it can keep cannot be larger than $\underline{W}+\bar{W}$, where $\bar{W}$ is the parameter that puts the upper bound on the wealth kept in conjunction with $\underline{W}$. Hence, the transfer is determined as:

$$
\begin{aligned}
T R & =\Delta_{W} \mathbf{I}_{i}^{k_{i}=H^{M}}-W-\sum_{g=m, f} \mathbf{1}_{g} Y_{g}+\max \left\{Y_{j}, \underline{Y}\right\} \\
& +\min \{W, \underline{W}\}+\max \{0, \min [0.5(W-\underline{W}), \bar{W}]\} .
\end{aligned}
$$

For the parameters used to specify the exact Medicaid eligibility criteria (and hence the transfers according to the above equations), there are variations across states. We calibrate these parameters based on the rule from Pennsylvania (see Section 5).

\subsubsection{Full dynamic problem}

Given that the optimization problem faced in each period and state variables are specified above, now we explain how state variables evolve over time. Given the 
choices made in each period, the budget constraint (Equation 14) determines the next period's wealth. Each member's health $\left(h_{m}, h_{f}\right)$ evolves following a first-order Markov process, where there are five states: $G, B, A D L L, A D L H$, and Death $(D)$ as the absorbing state. The health transition matrix is a function of age, gender, marital status (single versus coupled), and permanent income (PI) of households. Retirement income $\left(\left\{Y_{m}, Y_{f}\right\}=\mathbf{Y}\right)$ does not change over time except when a member is widowed and starts receiving a survivor benefit: This member is reassigned the larger value in the couple's income vector. ${ }^{19}$ Lastly, the family situation $(F)$ changes when one is widowed. Not only does that household becomes single, but also for households with a child outside the 10-mile radius, we allow for a $50 \%$ chance that a child moves within the 10 -mile radius. We made this modeling choice to be consistent with the observations from the HRS data.

The full maximization problem can be stated with the following Bellman equation:

$$
\begin{aligned}
V(t, W, \mathbf{h}, \xi, F, \mathbf{Y} ; P I) \quad & =\max _{\mathbf{c}, \mathbf{q}, \mathbf{k}}\{U(\mathbf{c}, \mathbf{q}, \mathbf{k} ; \mathbf{h}, \boldsymbol{\xi}, F)+ \\
& \left.\beta \mathbf{E}\left[\eta(t, \mathbf{h}, F ; P I) V\left(t+1, W^{\prime}, \mathbf{h}^{\prime}, \boldsymbol{\xi}^{\prime}, F^{\prime}, \mathbf{Y}^{\prime} ; P I\right)+(1-\eta(t, \mathbf{h}, F ; P I)) b\left(W^{\prime}\right)\right]\right\},
\end{aligned}
$$

subject to the budget constraint (Equation 14), the transfer rules (Equations 15 to 17), the stochastic transitions of health and associated transitions of retirement income and family status explained above. $\beta$ is a time discount factor, $\eta$ is the probability of survival, and $b$ is the bequest utility function.

\footnotetext{
19 This is based on the following observations. For Social Security, though many factors including the age of the widowed spouse and when the deceased started collecting her/his benefits affect the exact rule applied, one common situation is that the widowed spouse may choose her/his own benefit or $100 \%$ of the deceased spouse's benefits. For defined-benefit pensions, Johnson, Uccello, and Goldwyn (2003) report that the vast majority (72\%) of men, who are more likely to have higher retirement income, choose joint-and-survivor pensions, while a small fraction (31\%) of women do so.
} 
This optimization problem's solution gives rise to the individual demands for nursing home beds that depends on $P_{j}$ and $Q_{j}$ for out-of-pocket patients and $Q_{j}$ for Medicaid patients.

\subsection{Nursing homes}

There are $J$ nursing homes in a single nursing home market. Preference shocks $\left(\xi_{g}^{k}\right)$ in the household's problem allow us to handle the local competition among the nursing homes in a tractable way.

Nursing home $j$ takes as given prices and care intensity of the market's other nursing homes and maximizes profits by choosing its price and intensity:

$$
\begin{array}{cl}
\max _{P_{j}, Q_{j}} & n_{j}\left(P_{j}, Q_{j}\right) P_{j}+m_{j}\left(Q_{j}\right) M-c\left(N_{j}, Q_{j}\right)-\chi, \\
\text { where } & N_{j}=n_{j}\left(P_{j}, Q_{j}\right)+m_{j}\left(Q_{j}\right),
\end{array}
$$

where $\chi$ is the per-period fixed cost of operation and $M$ is the Medicaid reimbursement rate. $n_{j}($.$) and m_{j}($.$) are residual demands for nursing home j$ from private payers and Medicaid enrollees, respectively. $N_{j}$ is the total number of patients. Note that the demand from Medicaid enrollees depends only on the care intensity of the nursing home, while that from private patients depends on both price and intensity. The variable cost function $c$ is an increasing function of the number of patients and the care intensity.

The first order conditions are similar to the ones derived in Section 3:

$$
\begin{aligned}
& \partial P_{j}: \quad-\left(P_{j}-c_{N}\left(N_{j}, Q_{j}\right)\right) \frac{\partial n_{j}}{\partial P_{j}}=n_{j}\left(N_{j}, Q_{j}\right), \\
& \partial Q_{j}: \quad\left(M-c_{N}\left(N_{j}, Q_{j}\right)\right) \frac{\partial m_{j}}{\partial Q_{j}}+\left(P_{j}-c_{N}\left(N_{j}, Q_{j}\right)\right) \frac{\partial n_{j}}{\partial Q_{j}}=c_{q}\left(N_{j}, Q_{j}\right) .
\end{aligned}
$$




\subsection{Equilibrium}

Given the exogenous policy parameters, including the Medicaid reimbursement rate $(M)$ and eligibility rules, the nursing home market's equilibrium is composed of the following objects: ${ }^{20}$ The value function $(V)$; the policy function for consumption,

$\left\{c_{g}\right\}_{g=m, f}$; the policy functions for type and intensity of care, $\left\{k_{g}, q_{g}^{k}\right\}_{g=m, f}$; the prices and intensity set by nursing homes, $\left\{P_{j}, Q_{j}\right\}_{j=1}^{J}$; the nursing home demand, $\left\{n_{j}, m_{j}\right\}_{j=1}^{J}$; and the joint distribution of households over individual states that satisfy the following conditions.

1. Given the price and care intensity set by nursing homes and the Medicaid rules, the value and policy functions of the households solve the maximization problem (Equation 18.

2. Given the household demand, Medicaid reimbursement policy, and prices and intensity set by its competitors, the price and intensity set by each nursing home maximize its profit (Equation 19).

3. The nursing home market clears.

4. The joint distribution of households is consistent with their decision rules.

\subsection{Computation}

Given the prices and care intensity set by the nursing homes $\left(\left\{P_{j}, Q_{j}\right\}_{j=1}^{J}\right)$, the households' optimization problems can be solved by backward induction. We solve the static maximization problem of the households whose age is the largest value allowed

\footnotetext{
${ }^{20}$ We omit the state variables and age subscript for brevity.
} 
$(T)$, then use the value function at age $T$ as the continuation value for the maximization problem at $T-1$, and so forth.

In our model, nursing homes face the same cost structure and preference shocks drawn from identical distributions. This ensures symmetric demand across nursing homes. Therefore, we can focus on a symmetric equilibrium where all the nursing homes choose the same price and intensity. To check that a certain price and intensity combination $\left(P^{*}, Q^{*}\right)$ represent equilibrium values, we numerically evaluate the derivative terms in the first order conditions of the nursing homes (Equations 21 and 22) by re-solving the household's problem assuming that one nursing home slightly deviates from $\left(P^{*}, Q^{*}\right)$, and then examine whether $\left(P^{*}, Q^{*}\right)$ satisfy the first order conditions.

\section{Calibration}

We calibrate the parameters with standard values used in the literature or with data for direct estimation before solving the model. We calibrate the other parameters such that the model's key moments match the empirical counterparts. Table 3 lists the parameters in the model and the calibrated values. In the rest of this subsection, we explain the calibration in more detail.

\subsection{Preferences}

We use a standard CRRA utility function for noncare consumption:

$$
v(c)=\frac{c^{1-\gamma_{1}}}{1-\gamma_{1}} .
$$

We set $\gamma_{1}=3$, which is a standard value in the literature. 
Table 3: List of the parameters calibrated

\begin{tabular}{llll}
\hline Parameter & Value & Description & Source/Target \\
\hline A. Taken from the literature & & Risk aversion over noncare consumption & Standard value \\
$\gamma_{1}$ & 3 & Time discount factor & Standard value \\
$\beta$ & 0.97 & Real interest rate & \\
$r$ & 0.03 & Bequest utility function parameters & Ameriks et al. (forthcoming) \\
$\theta_{b}, \kappa_{b}$ & $1,-\$ 8 \mathrm{~K}$ & Consumption value of OOP stay at a NH & Hackmann $(2019)$ \\
$\Delta_{N}^{O}$ & $\$ 20 \mathrm{~K}$ & HCBC per hour cost w/o family support & Mommaerts $(2016)$ \\
$\rho$ w/o family & $\$ 35$ & Fixed cost of using HCBC & Achou (2016) \\
$\Psi$ & $\$ 20 \mathrm{~K}$ & W/o family support & Hackmann $(2019)$ \\
$M$ & $\$ 76.5 \mathrm{~K}$ & Medicaid reimbursement rate for NHs & Supplemental Security Insurance \\
$\Delta_{W}$ & $\$ 10 \mathrm{~K}$ & Consumption under welfare & Hackmann (2019) \\
$\chi$ & $\$ 1.3 \mathrm{M}$ & NH fixed cost of operation & HRS data \\
\hline B. Estimated from the data & & & PA Department of Health data \\
$\Pi_{H}$ & See Appendix A & Health transition matrices & PA Medicaid rules \\
$J$ & 11 & Number of nursing homes & \\
$\underline{Y}, \underline{W}, \bar{W}$ & $\$ 25 \mathrm{~K}, \$ 60 \mathrm{~K}, \$ 120 \mathrm{~K}$ & Medicaid eligibility parameters & \\
\hline
\end{tabular}

Note: Dollar values are in 2017 dollars. Flow variables are reported in terms of per-year values. 
Table 3: List of the parameters calibrated (continued)

\begin{tabular}{|c|c|c|c|}
\hline Parameter & Value & Description & Source/Target \\
\hline \multicolumn{4}{|c|}{ C. Calibrated in the model } \\
\hline$\gamma_{2}$ & 1.2 & Risk aversion over care consumption & Mean/median ratio in $q$ under ADLH \\
\hline$\theta_{h}, \kappa_{h}$ & $\begin{array}{l}0.0009,300 \text { for } h=A D L H \\
0.00021,50 \text { for } h=A D L L\end{array}$ & Care utility function parameters & Mean and 25-pctl of $q$ \\
\hline$\sigma_{\xi}$ & 0.1 & S.d. of preference shocks & $\begin{array}{l}\text { Share of care type choice } \\
\text { explained by observables }\end{array}$ \\
\hline$\Delta_{N}^{M}$ & $\$ 10.1 \mathrm{~K}$ & $\begin{array}{l}\text { Consumption value of } \\
\text { Medicaid stay at a } \mathrm{NH}\end{array}$ & Share of $\mathrm{NH}$ among Medicaid patients \\
\hline$\rho \mathrm{w} /$ family & $\$ 17.5$ & HCBC per hour cost w/ family resources & $\begin{array}{l}\text { Difference in the HCBC share } \\
\text { between } \mathrm{w} / \text { and } \mathrm{w} / \mathrm{o} \text { family }\end{array}$ \\
\hline$c$ & 0.177 & Level of $\mathrm{NH}$ cost function & Profit after the fixed cost \\
\hline$\alpha, \beta$ & $1.277,0.665$ & Returns to scale in $\mathrm{NH}$ cost function & $\begin{array}{l}\text { Satisfying (21) and (22) } \\
\text { at } P_{j}=\$ 85 K \text { and } Q_{j}=2,000\end{array}$ \\
\hline
\end{tabular}

Note: Dollar values are in 2017 dollars. Flow variables are reported in terms of per-year values. 
For care consumption, we use a CRRA utility function with a subsistence level of care consumption $\left(\kappa_{h}>0\right)$ :

$$
u(q ; h)=\frac{\left(q-\kappa_{h}\right)^{1-\gamma_{2}}}{1-\gamma_{2}} .
$$

The subsistence level of care consumption governs the left tail of the distribution of care hours used $(q)$. We set it to be 300 hours per year for $h=A D L H$ and 50 hours per year for $h=A D L L$ to match the 25th percentiles of the distribution of $q$ from the model to their empirical counterparts, conditional on $h$. Note that with the utility multiplier, $\theta_{h}$, in the overall flow utility function (Equation 13), our utility function essentially has the same functional form as in Ameriks et al. (forthcoming). The utility multiplier affects the overall level of care consumption. We set it to match the average care hours used, conditional on being ADLL and ADLH, separately. We allow preferences over care and noncare consumption to differ in the risk aversion. In fact, to reproduce the data's long right tail of care hours, the model requires that the marginal utility of care consumption diminishes more slowly than that of the noncare consumption utility function, achieved with $\gamma_{2}<\gamma_{1}$. More specifically, we target the mean/median ratio of care hours under $A D L H$, and set $\gamma_{2}=1.2$. When in need of long-term care, preference shocks $\left(\xi^{k}\right)$ affect the choice of care. The larger the variance of preference shocks, the more choice is driven by factors not explicitly modeled, so the care choice becomes more random. The standard deviation of $\xi^{k}$ targets the share of care-type choices explained by the observables (see Section 5.6). 
We set the risk-free interest rate $(r)$ to be $3 \%$ per year and the time discount factor $(\beta)$ such that $\beta=\frac{1}{1+r}$. Following Ameriks et al. (forthcoming), we use the following functional form for the bequest utility function:

$$
b(W)=\theta_{b} \frac{\left(W-\kappa_{b}\right)^{1-\gamma}}{1-\gamma}
$$

where $\theta_{b}$ determines the overall strength of the bequest motive while $\kappa_{b}<0$ makes the bequest a luxury good compared to noncare consumption. Based on the estimates from Ameriks et al. (forthcoming), we set $\theta_{b}=1$ and $\kappa_{b}=-\$ 8 K$.

\subsection{Initial joint distribution and health transitions}

The model starts from age 70 and individuals can live to age $110(T=110)$. To obtain the initial joint distribution of the state variables at the youngest age (70), we use the cross-section of the following households from a single wave (HRS 2014): (i) single households between ages 68 and 72; (ii) coupled households with an average age between 68 and 72 and where the spouses' age difference is less than 10 years. There are 1,247 such households.

Starting from this initial joint distribution, we generate a representative population of Americans older than 70 from the model by simulating their health transitions using the transition matrices estimated from the HRS data. ${ }^{21}$ Note that we do not allow for population aging as we focus on the stationary distribution in a nursing home market.

\footnotetext{
21 To reduce the sampling error in the simulation, we create 100 clones of each household from the initial joint distribution. We apply the sampling weights from the HRS in all the analyses in this paper. The sampling weights are rescaled to make the total elderly population in the model the same as that in an average nursing home market $(24,000)$ according to the Pennsylvania Department Health data and the census.
} 
The transition matrices over the five health states $(G, B, A D L L, A D L H$, and death as the absorbing state) are functions of each member's age and gender, whether single or coupled, as well as the household's permanent income, (PI), as in Jones et al. (2018). We measure the permanent income as the sum of Social Security and definedbenefit pension incomes because that can be considered as a proxy for households' lifetime earnings. See Appendix A for more details on the transition matrix estimation.

\subsection{Long-term care costs}

A nursing home stay's out-of-pocket cost and care intensity is determined in the equilibrium, as an outcome of local competition among nursing homes. As explained below, we calibrate the parameters in the nursing home cost function such that the equilibrium price $\left(P_{j}\right)$ and the intensity $\left(Q_{j}\right)$ - which are common across nursing homes in the symmetric equilibrium - are $\$ 85,000$ per year and 2,000 hours per year, respectively. These are based on the Nursing Home Reports data for the former and the standard value used in the literature for the latter (e.g., Mommaerts 2016). Regarding the consumption value of an out-of-pocket nursing home stay $\left(\Delta_{N}^{O}\right)$, Hackmann (2019) reports that the nonhealth-related resident cost for a nursing home is about one-third of the health-related cost. Based on this, we assume that $\Delta_{N}^{O}=\$ 20,000$, approximately a quarter of the out-of-pocket expense. We calibrate $\Delta_{N}^{M}$ to be $\$ 10,100$, about half of $\Delta_{N}^{O}$, to match the share of Medicaid patients that enter a nursing home, which is an increasing function of this parameter.

The HCBC expenses are composed of two parts for those without family support: The per-unit price ( $\rho_{N F}$, where $N F$ stands for no family support) and the fixed cost of using $\operatorname{HCBC}(\Psi)$. We calibrate $\rho_{N F}$ to be $\$ 35$ per hour, based on the formal, heavy-care 
cost used in Mommaerts (2016). $\Psi$ captures the fact that to receive care at home while not having any family to rely on, the patient also has to purchase services to replace basic home production. Achou (2016) reports that the average home production among older couples is between 1,000 to 1,500 hours per year. We calibrate $\Psi$ to be $\$ 20,000$ per year based on this information. We assume that individuals with family support do not face a fixed cost of using HCBC. In addition, we allow the HCBC unit cost to be lower for those with family to reflect the care providers' lower opportunity costs (foregone wages and/or leisure). ${ }^{22}$ We calibrate $\rho_{F}$ to be half of $\rho_{N F}$, to match the difference in the share of HCBC between those who do and do not have family support.

Note that, for private patients whose demand for care is close to 2,000 hours per year and without family support, entering a nursing home is a more cost-effective option than using HCBC. Given that a nursing home stay comes with $\$ 20,000$ of consumption value, the effective cost of 2,000 hours of care is $\$ 65,000$. For $\mathrm{HCBC}$, individuals without family support need to spend $\$ 70,000$ to receive 2,000 hours of care ( $\$ 35 \times$ $2000)$, so even without taking into account the fixed cost of using $\mathrm{HCBC}(\Psi), \mathrm{HCBC}$ is a more expensive option. This reflects the increasing returns to scale over the care intensity feasible under the institutional setup (see below). Of course, for those whose demand for care is not close to 2,000 hours per year, or for those with family support, HCBC will be a more economical option.

\footnotetext{
22 If the informal care is provided by an already retired, healthy spouse, the opportunity cost is composed only of foregone leisure. Even for the other cases, the effect of informal caregiving on labor supply is significant only for highly-intensive caregiving (Butrica and Karamcheva 2014).
} 


\subsection{Medicaid rules and SSI transfer}

There are variations across states in how much income and wealth households with a Medicaid patient and a healthy spouse can keep. We calibrate the parameters in this rule based on Pennsylvania. ${ }^{23}$ The minimum amount of income to be kept $(\underline{Y})$ is set to be $\$ 25,000$, which is the average between the minimum $(\$ 20,000)$ and the maximum $(\$ 30,000)$ values of the Minimum Monthly Maintenance Needs Allowance set by the federal government. The threshold up to which households can keep the full value of its wealth $(\underline{\mathrm{W}})$ is set to be $\$ 60,000$, based on the fact that the spouse in the community can keep the house and the median value of home equity among couples and under Medicaid in the HRS is $\$ 60,000$. The maximum amount of wealth those households can keep, in addition to the home equity $(\bar{W})$, is $\$ 120,000$ in Pennsylvania.

The Medicaid reimbursement rate $(M)$, the amount that Medicaid pays to nursing homes per Medicaid patient, is set to be $\$ 76,500$ based on Hackmann (2019). This is $10 \%$ lower than the out-of-pocket price.

We also model a transfer program that allows for the noncare consumption floor $\left(\Delta_{W}\right)$ for the households with insufficient resources. We set $\Delta_{W}$ to be $\$ 10,000$ per year based on the Supplemental Security Income.

\subsection{Nursing home costs}

Nursing homes incur a fixed cost of operation $(\chi)$, set to be $\$ 1.3$ million per year based on Hackmann (2019). The variable cost function is governed by three parameters: $c$ sets the overall level of the cost, and $\alpha$ and $\beta$ determine the returns to scale over the number of patients and the care intensity, respectively. We set $c$ such

${ }^{23}$ https://www.medicaidplanningassistance.org/medicaid-eligibility-pennsylvania 
that, at the equilibrium price $\left(P_{j}=\$ 85 \mathrm{~K}\right)$ and intensity $\left(Q_{j}=2,000\right.$ hours $)$ in the baseline, each nursing home has the level of profit that is positive net of the fixed cost of operation $(\chi)$ but not too large. At such a level of profit, the current number of nursing homes $(J=11)$ can be supported as an equilibrium. Setting $c=0.177$ generates such a level of profit (see Section 5.6 for more details). $\alpha$ and $\beta$ are calibrated such that the FOCs (Equations 21 and 22) from the nursing home's maximization problem are satisfied at the equilibrium price and baseline intensity. The calibrated cost function suggests that the nursing homes have decreasing returns to scale over the number of patients $(\alpha=1.277>1)$ and increasing returns to scale over intensity $(\beta=0.665<1)$. The former reflects the capacity constraint on the number of beds, and keeps the size of nursing homes consistent with that observed in the data - on average about 140 patients per nursing home. The latter may reflect that additional measures they take to increase the intensity of care (e.g., hiring skilled nursing staff and specialists, purchasing better medical equipment) can be efficiently shared by patients in the institutional set up where all patients use the same type of care. This is not possible, for example, for home care.

\subsection{Model fit}

In this subsection, we show that our quantitative model matches the targeted moments well, on the intensive margin (the number of care hours used) as well as the extensive margin (the care type used). We also test the model performance on some nontargeted moments. 
Table 4 presents the targeted moments. ${ }^{24}$ Empirical and model-generated moments line up very closely. Panel A shows that the model does a good job in matching the intensive margin of the distribution conditional on health status, in terms of the average (the target for $\theta_{h}$ ), the 25th percentiles (the target for $\kappa_{h}$ ), and the mean-tomedian ratio (the target for $\gamma_{2}$ ). On the extensive margin, conditional on being $A D L H$, those who have family support - i.e., those with either a healthy spouse or a child within 10 miles - are 24 percentage points more likely to use $\mathrm{HCBC}$. This is generated from the model by having the effective $\mathrm{HCBC}$ cost to be much lower for those with family support $\left(\rho_{F}\right)$ than for those without family support $\left(\rho_{N F}\right)$. For those on Medicaid, entering a nursing home and using $\mathrm{HCBC}$ are equally likely, which is generated by having the consumption value of being in a nursing home as a Medicaid patient $\left(\Delta_{N}^{M}\right)$ to be about the same as the consumption floor guaranteed for a Medicaid patient using $\operatorname{HCBC}\left(\Delta_{W}\right) \cdot{ }^{25}$

\footnotetext{
${ }^{24}$ Note that the median of care hours under ADLL as well as the overall levels of the HCBC share are not targeted.

${ }^{25}$ Recall that we assume a Medicaid nursing home stay and using HCBC as a Medicaid patient are equal in terms of the care intensity, i.e., $q=2,000$.
} 
Table 4: Model fit for the targeted moments

\begin{tabular}{|c|c|c|c|c|c|}
\hline $\begin{array}{l}\text { A. Care hours distribution } \\
\text { Health status }\end{array}$ & $25 p$ & $50 p$ & $75 p$ & Mean & $\mathrm{N}$ \\
\hline \multicolumn{6}{|l|}{ Data } \\
\hline ADLH & 1,188 & 2,000 & 3,720 & 2,574 & 1,723 \\
\hline ADLL & 288 & 744 & 2,000 & 1,355 & 1,205 \\
\hline \multicolumn{6}{|l|}{ Model } \\
\hline ADLH & 1,238 & 2,000 & 2,000 & 2,493 & \\
\hline ADLL & 248 & 840 & 2,000 & 1,320 & \\
\hline \multicolumn{6}{|l|}{ B. Share of HCBC (under ADLH) } \\
\hline Conditions & & & & Share of HCBC (\%) & $\mathrm{N}$ \\
\hline \multicolumn{6}{|l|}{ Data } \\
\hline Have family resources & & & & 73 & 1,408 \\
\hline Do not have family resources & & & & 49 & 315 \\
\hline On Medicaid & & & & 49 & 486 \\
\hline \multicolumn{6}{|l|}{ Model } \\
\hline Have family resources & & & & 75 & \\
\hline Do not have family resources & & & & 51 & \\
\hline On Medicaid & & & & 47 & \\
\hline
\end{tabular}

Note: Tabulation uses the sample in their 80 s. For the care hour distribution, a nursing home stay is coded as 2,000 hours per year.

Our quantitative model's main focus is to reproduce the LTC demand patterns across health, family status, and financial resources. The targeted moments mostly span the first two dimensions. In Figure 5, we examine the model's ability to reproduce patterns of LTC use across wealth and income quartiles, which were not targeted in the calibration. The empirical moments in Figure 5 (Panels a and c), which is a reproduction of Panel A of Table 2, show that the share of $\mathrm{HCBC}$ has an inverted U-shape over financial resources, in particular over wealth. At first, it increases with financial resources and then decreases. Exactly the same patterns are generated from the model (Panels $b$ and d), though these are not targeted. The sizes of the slopes are also similar between the data and the model. The only dimension with a gap is over income quartiles for those with family: The empirical moments are mostly flat while the model 
moments increase with income. So overall, our model is successful in accounting for how health, family, and financial resources affect the key long-term care choices.

Figure 5: Share of HCBC (\%): Conditional on family and financial resources

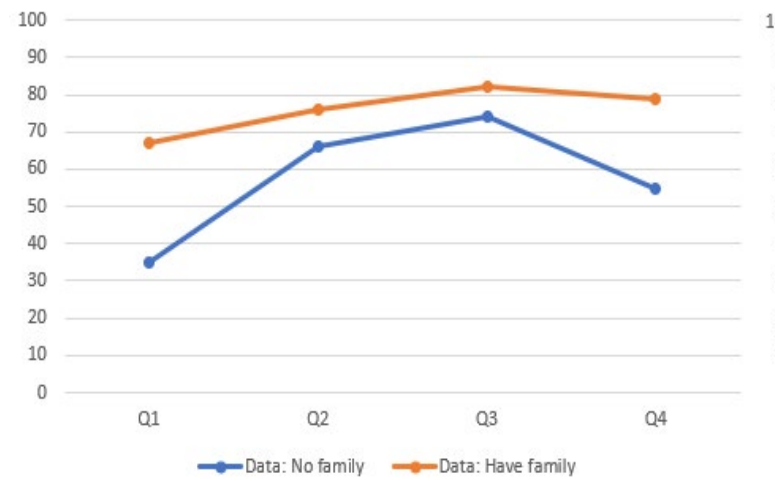

(a) By wealth quartiles, data

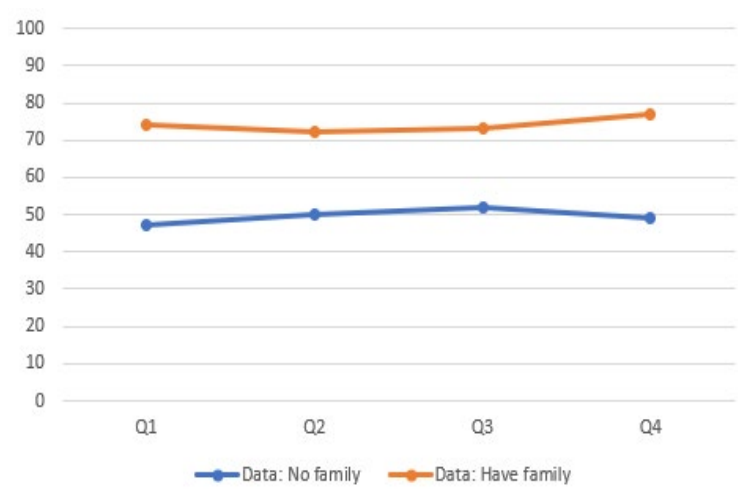

(c) By income quartiles, data

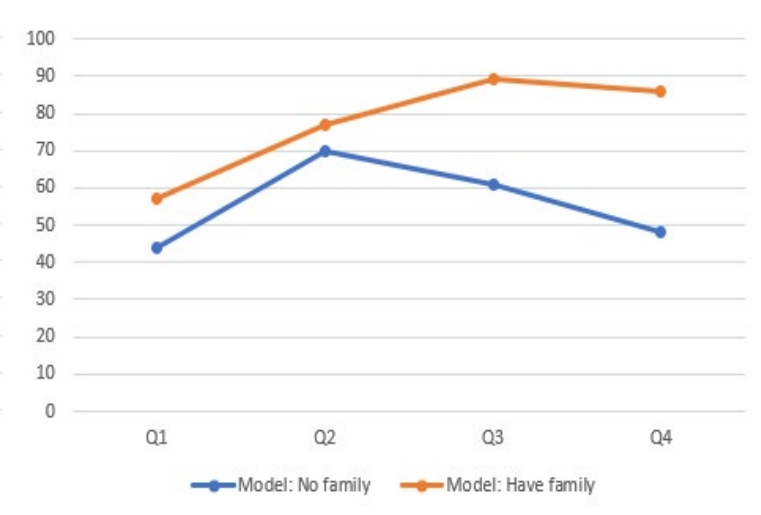

(b) By wealth quartiles, model

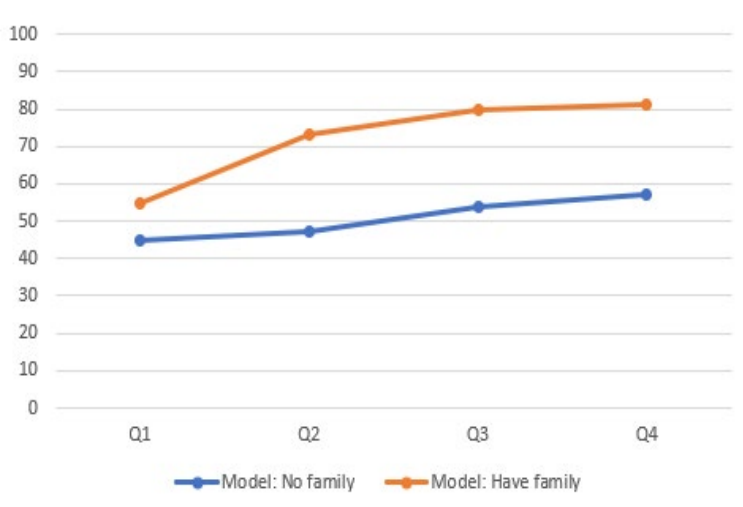

(d) By income quartiles, model

Note: Figure uses the sample in their 80 s and under ADLH. 
To see what forces in the model generate the observed moments, Figure 5 shows how the likelihood of choosing each care option varies as a function of family support and financial resources for an 80-year-old single male under $A D L H$. The patterns are essentially the same as what the stylized model (Section 3) predicts, except that the quantitative model now also allows for roles of unobserved factors in the form of preference shocks (hence, the choices are not deterministic). To see the impact of income, we compare the figures in the left with a very high income level ( $\$ 1$ million per year) and those on the right with a very low income level ( $\$ 10,000$ per year). For those with a high income level, Medicaid is never a relevant option. When they have almost no wealth other than income, they would prefer using $\mathrm{HCBC}$ over entering a nursing home, as their desired intensity of care is below 2,000 hours per year. As the wealth level goes up, the optimal care intensity approaches 2,000 hours per year, which means that entering a nursing home becomes more attractive. Indeed, for those who do not have family support (the top-left figure), entering a nursing home becomes more likely to be chosen for wealth levels between $\$ 12,000$ and $\$ 250,000$ (log of wealth between 2.5 and 5.5). For those with families (the bottom-left figure), HCBC stays as a dominant option at any wealth level. For those with a low income level, if they haven't accumulated enough wealth, they will be a Medicaid patient. For them, entering a nursing home and using $\mathrm{HCBC}$ is almost equally likely. As we increase the wealth level, we see that at some point, using $\mathrm{HCBC}$ out of pocket becomes a dominant option. They have too many financial resources to be a Medicaid patient, but too little to enter a nursing home out of pocket. The wealth level where the out-of-pocket HCBC becomes a dominant option is lower for those with family resources (the bottom-right figure) than for 
those without family resources (the top-right figure). Again, entering a nursing home becomes more attractive as the wealth level further increases, resulting in the inverted U-shape of the HCBC share over financial resources.

Figure 6: Likelihood of choosing care options (ADLH, 80 years old)
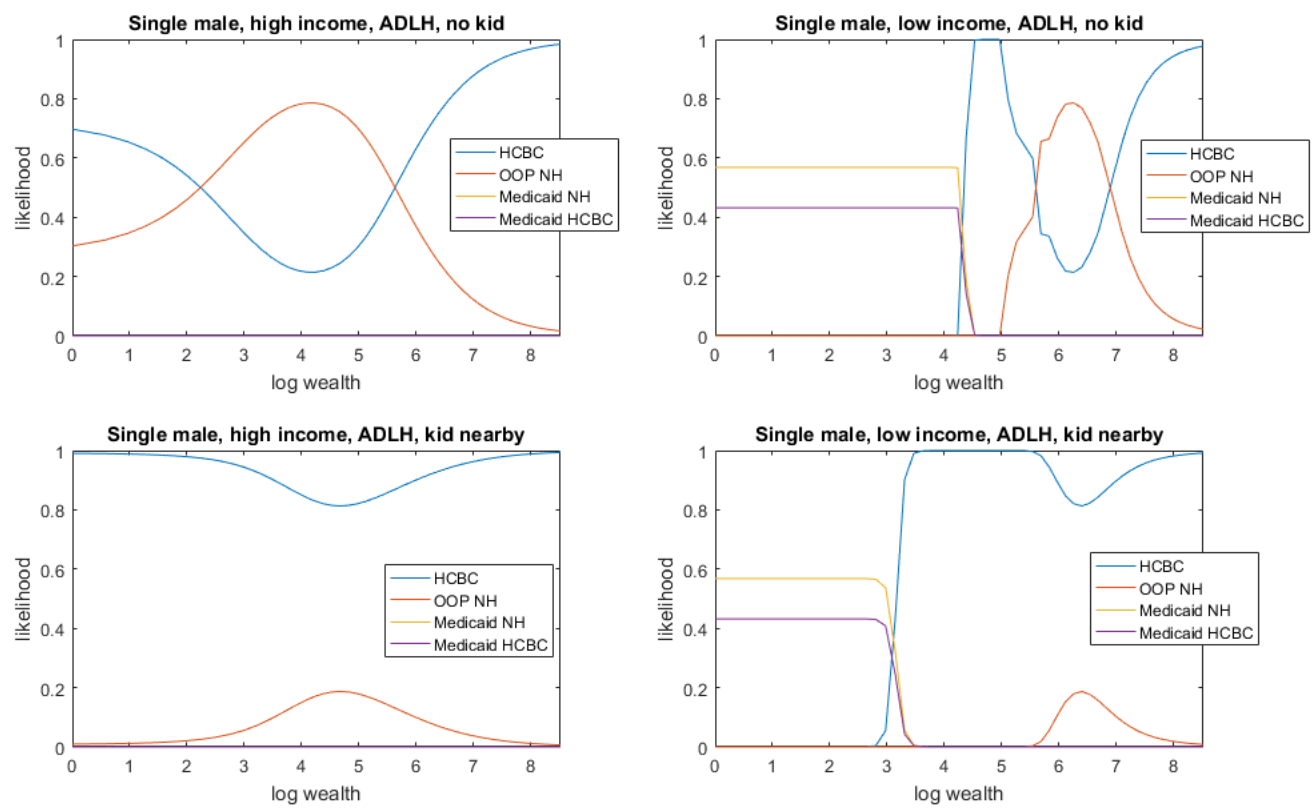

Note: The unit of the horizontal axis is log of wealth, where wealth is measured in multiples of $\$ 1,000$. For example, log wealth of 4 corresponds to the wealth level $\exp (4) \times \$ 1,000=\$ 55,000$.

At the equilibrium price $\left(P_{j}=\$ 85,000\right)$ and intensity $\left(Q_{j}=2,000\right)$, each nursing home has about 140 patients, where three-quarters of those are Medicaid patients. The revenue for each nursing home is about $\$ 10.7$ million, while the variable cost is $\$ 7.5$ million, making the annual profit before the fixed cost to be around $\$ 3.2$ million. This is larger than the fixed operational cost (\$1.3 million), but arguably not large enough to make profitable a new nursing home's entry into the market if we also take into account 
entry costs not modeled. Hence, the calibrated number of nursing homes $(J=11)$ is supported as an equilibrium in the market.

\section{Policy experiments}

In this section, we use our quantitative model to investigate the effects of LTSS policy experiments on households, nursing homes, and Medicaid expenditures. We first examine two policy experiments that target the market's supply-side and then study two policy experiments that target the market's demand-side. For each policy considered, we examine how equilibrium price and nursing home care intensity, as well as demand for it, change compared to the baseline model. We also show changes in the consumer surplus and its distribution over heterogeneous households, producer surplus, and Medicaid expenditures to examine the efficiency, as well as the distributional impacts, of the considered policy. ${ }^{26}$ For all the experiments, we highlight the importance of fully capturing the feedback between the changed household demand and nursing homes' pricing and intensity decisions in correctly assessing the policy outcomes.

\subsection{Supply-side targeted policy experiments}

In this section we examine two public policies targeting the supply side of the nursing home market: (i) an increase in the Medicaid reimbursement rate for nursing

\footnotetext{
${ }^{26}$ The consumer surplus is calculated as one-time wealth transfers that need to be made to the youngest households (age 70) in the baseline model to give them the same utility as with the policy experiment. The policies will affect the welfare and behavior of even those households that do not currently need LTC as forward-looking households take into account the changes in LTC options and better or worse insurance provided by Medicaid under the considered policy. Also, we do not model how additional funds needed to implement the policies are financed. Therefore, we do not take into account the distortionary effects of taxes used to finance the policy change.
} 
homes, and (ii) a nursing home entry subsidized by the government. There is a large literature assessing the effects of Medicaid reimbursement rates on nursing home care intensity. While theory predicts positive effects (Gertler 1989, and Nyman 1985), nonstructural estimation produced various results (see Grabowski 2001 for a review). More recently, Hackmann (2019) used a structural approach to estimate effects of Medicaid reimbursement policy, as well as subsidized entry of a nursing home. Our quantitative analysis complements the work of Hackmann (2019) in that we incorporate a microfounded demand side into our analysis.

\subsubsection{More generous Medicaid reimbursement}

The Medicaid reimbursement rate is based on the average variable costs faced by nursing homes in a given market. In the baseline model, based on the observations from Pennsylvania, it is set $10 \%$ below the out-of-pocket price. We now examine the effects of increasing the Medicaid reimbursement rate by $10 \%(\$ 7,650)$. The results of the experiment are reported in the second and third columns of Tables 5, (Columns 2 and 3), Table 6, and Table 7 (Columns 1 and 2).

As discussed in Section 3.2, higher return on Medicaid beds induces nursing homes to increase care intensity in order to attract more Medicaid residents but the effect on price and number of private beds is theoretically ambiguous. Table 5 reports that intensity increases by 68 hours per year (3.2\%), attracting about four additional Medicaid residents per nursing home. Higher care intensity and additional Medicaid residents increase the marginal bed cost by $\$ 1,900$ per year $(2.8 \%)$. Nursing homes pass this entirely to the private residents, increasing the price by the same amount $(2.2 \%)$. As a result, each nursing home loses 0.6 of the private bed, with a null change 
for private revenue due to the higher price. As each nursing home collects $\$ 1.13$ million $(13.9 \%)$ more in Medicaid reimbursements, the profits increase by $\$ 760,000$ or $37.4 \%$.

The increase in the care intensity we find is consistent with the estimates in Grabowski (2001) and Hackmann (2019). However, Hackmann (2019) finds a larger, $8.7 \%$ increase in intensity measured in care hours and the opposite effect on the out-ofpocket price, which declines by $4.5 \%$. Hackmann (2019)'s assumption of constant return to scale in the size of nursing home $(\alpha=1)$ removes one of the key channels through which the equilibrium price goes up — the increased marginal cost due to a larger number of patients. On the other hand, Hackmann (2019) models nonprofit nursing homes which place a nonmonetary value on the number of residents they admit, while our quantitative analysis abstracts from the differences in objective functions among nursing homes for tractability.

Table 5: Supply-side targeted policy experiments - effects on a nursing home

\begin{tabular}{lccccc}
\hline & Baseline & \multicolumn{2}{c}{ Increased Medicaid } & \multicolumn{2}{c}{ Subsidized } \\
& & reimbursement rate & \multicolumn{2}{c}{ entry of a NH } \\
& & $\boldsymbol{\Delta}$ & $\boldsymbol{\Delta} \%$ & $\boldsymbol{\Delta}$ & $\boldsymbol{\Delta} \%$ \\
\hline NH care intensity $\left(\boldsymbol{Q}_{\boldsymbol{j}}\right.$, hours per & 2,000 & +64 & +3.2 & -155 & -7.3 \\
year) & & & & & \\
NH price $\left(\boldsymbol{P}_{\boldsymbol{j}}, \mathbf{\$ K}\right)$ & 85.0 & +1.9 & +2.2 & -4.1 & -10.7 \\
Marginal cost $(\mathbf{\$ K})$ & 69.2 & +1.9 & +2.8 & -6.3 & -8.2 \\
Private residents & 31.2 & -0.6 & -1.9 & +4.3 & +13.8 \\
Medicaid residents & 106.2 & +3.8 & +3.6 & -19.5 & -18.4 \\
NH private revenue (\$M) & 2.65 & +0.01 & +0.0 & +0.05 & +1.9 \\
NH Medicaid revenue (\$M) & 8.13 & +1.13 & +13.9 & -0.50 & -18.4 \\
NH profits $(\mathbf{\$ M})$ & 2.03 & +0.76 & +37.4 & -0.08 & -3.9 \\
NH residents on Medicaid, \% & 77 & +1 & +1.3 & -8 & -7.8 \\
\hline
\end{tabular}


Given the small changes in price and intensity of nursing home care, the overall impact on the demand side is limited, but the policy has important distributional effects. Table 6 reports the consequences of higher price and intensity of nursing home care on the household LTC choice and care hours used. For the households at the bottom two wealth quartiles, the share of Medicaid residents increases. This reflects the reduced share of Medicaid HCBC patients for the bottom wealth quartile and the reduced share of private $\mathrm{HCBC}$ patients for the second wealth quartile. For the households in the third wealth quartile, the higher $\mathrm{NH}$ price induces some to switch to the private $\mathrm{HCBC}$ option. In terms of the average hours used, the policy reduces inequality by increasing usage for the bottom half of the wealth distribution while having a null effect on the other half.

Given the limited impact on the demand side, the increase in the Medicaid expenditure ( $\$ 10.9$ million) is mostly absorbed as additional producer surplus ( $\$ 8.4$ million), though the latter is slightly smaller due to the increased cost (Table 7, Panel A). ${ }^{27}$ The consumer surplus on average increases, but quantitatively it is very small $(\$ 400,000)$. Panel B of Table 7 reveals why the increase in consumer surplus is limited. Those who are more likely to be a Medicaid patient at some point — bottom three wealth quartiles - benefit from the higher nursing home care intensity, while those who are more likely to pay for nursing home out of pocket — the top wealth quartile — lose due to the higher price.

${ }^{27}$ In calculating the total Medicaid expenditure, we take the sum of Medicaid reimbursements to all 11 nursing homes and its expenditure on Medicaid HCBC patients, and then subtract the amount of financial resources Medicaid patients forfeit. There is no direct evidence on how much Medicaid pays for HCBC patients on average, so we assume it to be the same as the Medicaid reimbursement rate for nursing homes in the baseline model $(\$ 76.5 \mathrm{~K})$ for those without family support and a half that rate for those with family support. 
Table 6: Increase in the Medicaid reimbursement rate - effects on household care choices

\begin{tabular}{|c|c|c|c|c|c|c|}
\hline & \multicolumn{4}{|c|}{ Care type choice (\%) } & \multirow{2}{*}{\multicolumn{2}{|c|}{$\begin{array}{l}\text { Mean intensity } \\
\text { (hours per year) }\end{array}$}} \\
\hline & \multicolumn{2}{|c|}{ HCBC } & \multicolumn{2}{|c|}{ Nursing home } & & \\
\hline & Private & Medicaid & Private & Medicaid & All & $\begin{array}{c}\text { Private } \\
\text { HCBC }\end{array}$ \\
\hline \multirow[t]{2}{*}{ Age: $70-79$} & 62.2 & 12.9 & 4.5 & 20.4 & 1,889 & 1,795 \\
\hline & $(-0.2)$ & $(-0.4)$ & $(0.0)$ & $(+0.6)$ & $(+16)$ & $(-1)$ \\
\hline \multirow[t]{2}{*}{ Age: $80-89$} & 61.2 & 13.2 & 5.1 & 20.4 & 1,962 & 1,910 \\
\hline & $(-0.2)$ & $(-0.5)$ & $(-0.2)$ & $(+0.7)$ & $(+16)$ & $(-2)$ \\
\hline \multirow[t]{2}{*}{ Age: $90-99$} & 65.8 & 10.7 & 6.3 & 17.2 & 1,670 & 1,476 \\
\hline & $(0.0)$ & $(-0.4)$ & $(-0.2)$ & $(+0.6)$ & $(+12)$ & $(-5)$ \\
\hline \multirow[t]{2}{*}{ With family } & 65.9 & 12.5 & 2.8 & 18.9 & 1,925 & 1,865 \\
\hline & $(-0.3)$ & $(-0.3)$ & $(0.0)$ & $(+0.7)$ & $(+15)$ & $(0)$ \\
\hline \multirow{2}{*}{$\begin{array}{l}\text { Without } \\
\text { family }\end{array}$} & 53.1 & 11.8 & 13.9 & 21.3 & 1,559 & 1,126 \\
\hline & $(+0.4)$ & $(-0.6)$ & $(-0.4)$ & $(+0.6)$ & $(+14)$ & $(-10)$ \\
\hline \multirow[t]{2}{*}{ Wealth: Q1 } & 33.6 & 23.9 & 0.0 & 42.6 & 1,447 & 269 \\
\hline & $(0.0)$ & $(-1.2)$ & $(0.0)$ & $(+1.2)$ & $(+28)$ & $(-1)$ \\
\hline \multirow{2}{*}{ Wealth: Q2 } & 65.0 & 15.4 & 0.5 & 19.1 & 1,123 & 633 \\
\hline & $(-0.7)$ & $(-0.1)$ & $(-0.1)$ & $(+0.9)$ & $(+20)$ & $(-2)$ \\
\hline \multirow[t]{2}{*}{ Wealth: Q3 } & 87.1 & 1.5 & 9.2 & 2.1 & 1,309 & 1,198 \\
\hline & $(+0.5)$ & $(-0.1)$ & $(-0.6)$ & $(0.0)$ & $(+3)$ & $(-1)$ \\
\hline \multirow[t]{2}{*}{ Wealth: Q4 } & 82.5 & 0.0 & 17.5 & 0.0 & 4,288 & 4,758 \\
\hline & $(-0.1)$ & $(0.0)$ & $(+0.1)$ & $(0.0)$ & $(-3)$ & $(-15)$ \\
\hline
\end{tabular}

Note: This table includes all the individuals whose health is either ADLL or ADLH. The numbers in parentheses show the differences compared to the baseline. 


\section{Table 7: Supply-side targeted policy experiment — welfare evaluations}

\begin{tabular}{|c|c|c|c|c|}
\hline \multirow[t]{2}{*}{ A. Aggregates } & \multicolumn{2}{|c|}{$\begin{array}{l}\text { Increased Medicaid } \\
\text { reimbursement rate }\end{array}$} & \multicolumn{2}{|c|}{$\begin{array}{l}\text { Subsidized } \\
\text { entry of a NH }\end{array}$} \\
\hline & $\Delta$ level (\$M) & $\Delta \%$ & $\Delta$ level (\$M) & $\Delta \%$ \\
\hline Consumer surplus* & +0.4 & $\mathrm{NA}$ & +7.2 & NA \\
\hline Producer surplus & +8.4 & +37.4 & +1.1 & +4.9 \\
\hline Medicaid expenditures & +10.9 & +11.1 & $-9.8^{* *}$ & -9.1 \\
\hline $\begin{array}{l}\text { B. Distribution } \\
\text { Consumer surplus* } \\
\text { by wealth groups }\end{array}$ & \multicolumn{2}{|c|}{$\begin{array}{c}\Delta \text { level } \\
\text { (per household, \$) }\end{array}$} & \multicolumn{2}{|c|}{$\begin{array}{c}\Delta \text { level } \\
\text { (per household, \$) }\end{array}$} \\
\hline Wealth: Q1 & \multicolumn{2}{|c|}{+52} & \multicolumn{2}{|c|}{+221} \\
\hline Wealth: Q2 & \multicolumn{2}{|c|}{+364} & \multicolumn{2}{|c|}{-144} \\
\hline Wealth: Q3 & \multicolumn{2}{|c|}{+313} & \multicolumn{2}{|c|}{$+2,602$} \\
\hline Wealth: Q4 & \multicolumn{2}{|c|}{-32} & \multicolumn{2}{|c|}{$+12,002$} \\
\hline
\end{tabular}

Note: The table presents the changes compared to the values in the baseline model.

* The consumer surplus is calculated as one-time wealth transfers needed to be made to the youngest households (age 70 ) in the baseline model to give them the same utility as with the policy experiment. The number in Panel $A$ is the summation across households while those in Panel $B$ is the average within each wealth group.

** The change in the Medicaid expenditure in the subsidized $\mathrm{NH}$ entry experiment does not include the subsidy paid to a $\mathrm{NH}$ to reduce the entry cost.

Some households' welfare losses due to an increase in the equilibrium price can be captured only in a model that explicitly considers the interaction between the supply and demand sides in the nursing home market. If we only focused on the direct effect the increase in the care intensity — then the expected increase in the consumer surplus would have been larger, potentially leading to a conclusion that the increase in the Medicaid reimbursement rate is a cost-effective policy. Our quantitative model, which also captures the incentive of nursing homes to increase the price facing larger 
demand, in contrast, shows that the increase in the Medicaid expenditures is larger than the sum of the increases in the consumer and producer surpluses. ${ }^{28}$

\subsubsection{Incentivized entry of a nursing home}

In the baseline model equilibrium, there are 11 nursing homes, and each nursing home has an annual profit of $\$ 2 \mathrm{M}$ after accounting for the annual fixed operational cost. Equilibrium requires that the entry cost is large enough to discourage another nursing home's entry. Limited local competition results in high price of a nursing home bed and other distortions due to the market power. If Medicaid or other government programs cover the entry cost, however, it is possible to have an entrant that would increase market competition. Following Hackmann (2019), we consider the effect of having a directed entry of a nursing home. ${ }^{29}$

The direct impact of the policy is primarily on the supply side: Nursing homes face less demand as the patient pool is shared with the entrant. The direct effect is also present on the demand side: A higher number of nursing homes increases the likelihood of finding a better match (i.e., they now take the largest draw from 12, instead of 11 , draws of preference shocks, $\xi^{N H_{j}}$ ).

${ }^{28}$ Note that we assume that the policy does not affect the consumption value of a nursing home stay for a Medicaid patient $\left(\Delta_{N}^{M}\right)$, which is calibrated to be half of the consumption value of a nursing home stay for a private patient $\left(\Delta_{N}^{O}\right)$. If the gap between $\Delta_{N}^{M}$ and $\Delta_{N}^{O}$ reflects the public care aversion due to the stigma effect and if the policy removes such stigma, the increase in the consumer surplus could be larger. If the gap reflects the actual difference in the amenities provided to the two types of patients and if the policy removes such a difference by making nursing homes provide more amenities to Medicaid residents, then a part of the producer surplus in Table 7 would be captured as the consumer surplus.

29 Unlike Hackmann (2019), who considered a subsidized entry of a public nursing home, we consider a private nursing home entry. 
The nursing homes react to the reduced demand by changing their care intensity and prices. The impact of the increased demand on both intensity and price is theoretically ambiguous. As shown in Section 3.2, the incentives to change quality and price are determined by three channels: the slopes of the Medicaid and private demands, the marginal profit on each bed type and the marginal cost of extra intensity.

On the one hand, sharing the resident pool with more nursing homes means that the slopes of both the Medicaid demand and private demand over intensity $\left(\frac{\partial m_{j}}{\partial Q_{j}}\right.$ and $\frac{\partial n_{j}}{\partial Q_{j}}$ in Equation 22) are smaller, reducing incentives to provide higher quality. On the other hand, having fewer residents lowers marginal costs $\left(C_{N}\right.$ and $\left.C_{Q}\right)$ which increases incentives to provide higher intensity. Similarly, there are counteracting incentives for the price changes: The smaller number of out-of-pocket patients $\left(n_{j}\right)$ and the smaller marginal bed cost $\left(C_{N}\right)$ reduce the return to a higher price, while the smaller slope of demand over price $\left(\frac{\partial n_{j}}{\partial P_{j}}\right)$ reduces the marginal cost of increasing the out-of-pocket price (see Equation 21). Reflecting this theoretical ambiguity, the new entrant's effect on price and intensity of nursing home care in Hackmann (2019) varies across counties considered.

Our quantitative model shows that nursing homes reduce both care intensity and price: The last two columns in Table 5 show that intensity goes down by 155 hours per year $(-7.3 \%)$ and price declines by $\$ 4,100(-10.7 \%)$. Lower care intensity further reduces the Medicaid demand faced by each nursing home, resulting in a big loss of Medicaid residents ( $18.4 \%$ or 19.5 beds per nursing home). The number of private residents actually increases ( $13.8 \%$ or 4.3 beds per nursing home) due to the lower 
price. In the end, each incumbent nursing home has, on average, 15 fewer patients (an $11 \%$ loss). Therefore, the subsidized entry of a nursing home makes the incumbents smaller, cheaper, and lowers care intensity. The profit reduction is limited $(3.9 \%)$, as the revenue decrease is accompanied by a similar decrease in costs.

The additional nursing home does not simply absorb residents from other nursing homes, but creates reallocation of households across the care types. Moreover, as Table 8 shows, the households move in both directions: to and from institutional care. Nursing home residents from the wealth distribution's bottom half free Medicaid nursing home beds and become $\mathrm{HCBC}$ consumers, with the poorest quartile going to Medicaid $\mathrm{HCBC}$ and the second quartile to private HCBC. On contrary, LTC recipients who are older than 90, have no family, and in the wealth distribution's top half switch from private $\mathrm{HCBC}$ to private nursing home. The average hours of LTC decrease mostly due to the reduced intensity of the $\mathrm{NH}$ care. At the same time, the inequality in care consumption increases as the reduction is concentrated in the bottom two wealth quartiles while those in the top two wealth quartiles experience almost no change.

Unsurprisingly, higher competition increases the consumer surplus. The last two columns in Table 7, Panel A, show that the additional surplus is large, amounting to $\$ 7.2$ million. The gain is mostly driven by new nursing home residents in the top two wealth quartiles, who benefit from both the lower nursing home price and the larger selection of nursing homes. The Medicaid nursing home leavers, located in the bottom two wealth quartiles, gain virtually nothing, with the loss from the lower $\mathrm{NH}$ care intensity mitigated by other LTC options as well as the larger selection of nursing homes. 
Table 8: Subsidized entry of a nursing home - effects on household care choices

\begin{tabular}{lcccccc}
\hline & \multicolumn{3}{c}{ Care type choice (\%) } & \multicolumn{2}{c}{$\begin{array}{c}\text { Mean intensity } \\
\text { Nursing home } \\
\text { (hours per year) } \\
\text { All }\end{array}$} & $\begin{array}{c}\text { Private } \\
\text { Private } \\
\text { HCBC }\end{array}$ \\
\hline Age: 70-79 & 62.9 & 14.2 & 5.4 & 17.5 & 1,826 & 1,779 \\
& $(+0.5)$ & $(+0.9)$ & $(+0.9)$ & $(-2.3)$ & $(-47)$ & $(-17)$ \\
Age: 80-89 & 61.4 & 14.6 & 6.6 & 17.4 & 1,911 & 1,915 \\
& $(+0.0)$ & $(+0.9)$ & $(+1.3)$ & $(-2.3)$ & $(-35)$ & $(+3)$ \\
Age: 90-99 & 64.6 & 12.2 & 8.3 & 15.0 & 1,639 & 1,497 \\
& $(-1.2)$ & $(+1.2)$ & $(+1.8)$ & $(-1.7)$ & $(-19)$ & $(+16)$ \\
With family & 66.9 & 13.6 & 3.5 & 16.0 & 1,868 & 1,847 \\
& $(+0.7)$ & $(+0.8)$ & $(+0.7)$ & $(-2.2)$ & $(-42)$ & $(-18)$ \\
Without & 49.1 & 14.0 & 17.9 & 19.0 & 1,543 & 1,185 \\
family & & & & & & \\
& $(-3.6)$ & $(+1.6)$ & $(+3.6)$ & $(-1.7)$ & $(-2)$ & $(+49)$ \\
Wealth: Q1 & 33.3 & 28.4 & 0.0 & 38.3 & 1,365 & 271 \\
& $(-0.3)$ & $(+3.3)$ & $(0.0)$ & $(-3.1)$ & $(-54)$ & $(+1)$ \\
Wealth: Q2 & 67.4 & 15.9 & 1.3 & 15.4 & 1,050 & 630 \\
& $(+1.7)$ & $(+0.4)$ & $(+0.7)$ & $(-2.8)$ & $(-53)$ & $(-5)$ \\
Wealth: Q3 & 84.8 & 0.8 & 13.7 & 0.8 & 1,296 & 1,196 \\
& $(-1.8)$ & $(-0.8)$ & $(+3.9)$ & $(-1.3)$ & $(-10)$ & $(-3)$ \\
Wealth: Q4 & 81.0 & 0.0 & 19.0 & 0.0 & 4,297 & 4,871 \\
& $(-1.6)$ & $(0.0)$ & $(+1.6)$ & $(0.0)$ & $(+6)$ & $(+98)$ \\
\hline
\end{tabular}

Note: This table includes all the individuals whose health is either ADLL or ADLH. The numbers in parentheses show the differences compared to the baseline.

The producer surplus also increases. While each incumbent loses $\$ 80,000$, the entrant gains a profit of $\$ 1.95$ million, resulting in an overall increase in producer surplus by $\$ 1.1$ million. The unobserved entry cost makes it difficult to judge this policy's efficiency. If we do not take into account the entry cost, the total Medicaid expenditure decreasesby $\$ 9.8$ million. Most of this cost saving is because Medicaid enrollees reallocate from Medicaid nursing home to Medicaid HCBC. This is cheaper for Medicaid if recipients have family support, and some of individuals with family leave Medicaid altogether to use HCBC out of pocket. Therefore, whether this policy is cost effective or not depends on how the entry cost compares to the total gain of $\$ 18.1$ million. 
To sum up, stronger competition induced by a nursing home's subsidized entry reduces markups and increases the number of beds provided to out-of-pocket residents. At the same time, as nursing homes react to the changed demand by reducing the care intensity, the total number of beds used by the Medicaid residents decreases even with more nursing homes. The reaction of nursing homes causes distributional effects that favor wealthier households.

\subsection{Demand-side targeted policy experiments}

There is a large literature evaluating effects of Medicaid means-tested subsidies on households' savings and welfare (e.g., De Nardi, French, and Jones 2010, Kopecky and Koreshkova 2014, De Nardi, French, and Jones 2016, Braun, Kopecky, and Koreshkova 2017, and Achou 2020) as well as LTC choice (Grabowski and Gruber 2007, Mommaerts 2018).

Following this literature, we study two policies targeting the demand-side of the market: (i) an increase in Medicaid generosity by allowing single Medicaid residents to keep some wealth, and (ii) giving $\mathrm{HCBC}$ subsidies to those who do not have family.

\subsubsection{Increased Medicaid generosity}

In the baseline model, singles who become Medicaid recipients are not allowed to keep any significant amount of financial resources or home equity, following the current Medicaid eligibility criteria. De Nardi et al. (2011) and Warshawsky and Marchand (2017) show that, when it comes to the estate recovery, enforcement of this regulation appears to be limited. Based on this observation, Achou (2020) studies how strict enforcement of estate recovery affects older households' welfare. Motivated by this literature, we now examine how increasing Medicaid generosity, in the form of 
allowing single Medicaid recipients to keep wealth up to $\$ 20,000,{ }^{30}$ affects the nursing home market.

This policy change's direct impact is on the demand side: It increases the number of Medicaid recipients among singles. In particular, many of those who haven't chosen to be on Medicaid but could not afford to enter a nursing home as a private resident in the baseline model — hence ended up using limited hours of care under outof-pocket $\mathrm{HCBC}$ - will now be a Medicaid nursing home resident (see Section 3.1). In the absence of nursing homes' reactions, the number of Medicaid residents at nursing homes would increase by $24.3 \% .{ }^{31}$ This results in $\$ 300,000$ increase in the profit of each nursing home, or $\$ 3.3$ million increase in the total producer surplus.

Before reporting the nursing homes' reactions to the policy, it is important to weigh the nursing home incentives. As shown in Section 3.2, with almost no direct policy effect on the private demand, the price unambiguously increases. The policy effect on care intensity is ambiguous. The slope of Medicaid demand with respect to intensity $\left(\frac{\partial m_{j}}{\partial Q_{j}}\right)$, which affects the marginal return to raising intensity, changes through two channels: By changing the marginal individuals between the Medicaid nursing home and the $\mathrm{HCBC}$ option and by expanding the pool of Medicaid residents that nursing homes are competing over. The effect of the former channel is theoretically ambiguous (see Section 3.1, Proposition 4 (3)), while the effect of the latter channel unambiguously

\footnotetext{
$30 \$ 20,000$ is slightly less than half of the median home equity that couples on Medicaid keep in the HRS data.

${ }^{31}$ Its direct impact on the number of private residents is limited. It goes up by $1.9 \%$. This increase comes from the better insurance provided by a more generous Medicaid - hence households have an incentive to spend their resources more quickly by entering a nursing home out of pocket.
} 
increases the slope. At the same time, a larger number of Medicaid patients increases the marginal costs $\left(C_{N}\right.$ and $\left.C_{Q}\right)$, reducing the incentive to increase the intensity.

In our quantitative model, nursing home competition over the expanded Medicaid-resident pool dominates other channels, so the care intensity increases significantly, by 134 hours per year or $6.7 \%$ (Table 9). As expected, the price increases and by a lot $-\$ 11 \mathrm{~K}$ or $12.9 \%$. The large Medicaid-resident inflow, 36.6 individuals per facility or $34.5 \%$ (nearly a third larger than the direct impact), outweighs the outflow of private residents: 6.9 individuals per facility or $22.1 \%$. As a result, each nursing home ends up with nearly 30 more residents and a higher share of Medicaid beds ( $85 \%$ versus $77 \%$ ). Higher number of residents drives the marginal cost up by $10.1 \%$. While the markup on a private resident increases, the profit margin on a Medicaid bed shrinks. Although the total revenue from Medicaid beds increases by more than a third, nursing home profits decline by a small amount $(\$ 60,000$ or $3 \%)$.

Table 9: Demand-side targeted policy experiment - effects on a nursing home

\begin{tabular}{lccccc}
\hline & Baseline & $\begin{array}{c}\text { More generous } \\
\text { Medicaid }\end{array}$ & \multicolumn{2}{c}{$\begin{array}{c}\text { HCBC } \\
\text { subsidy }\end{array}$} \\
& & $\boldsymbol{\Delta}$ & $\boldsymbol{\Delta} \%$ & $\boldsymbol{\Delta}$ & $\boldsymbol{\Delta} \%$ \\
\hline NH care intensity $\left(\boldsymbol{Q}_{\boldsymbol{j}}\right.$, hours & 2,000 & +134 & +6.7 & -155 & -7.7 \\
per year) & & & & & \\
NH price $\left(\boldsymbol{P}_{\boldsymbol{j}}, \mathbf{\$ K}\right)$ & 85.0 & +10.9 & +12.9 & -3.9 & -4.5 \\
Marginal cost $(\mathbf{\$ K})$ & 69.2 & +7.0 & +10.1 & -5.9 & -8.5 \\
Private residents & 31.2 & -6.9 & -22.1 & -3.0 & -9.6 \\
Medicaid residents & 106.2 & +36.6 & +34.5 & -13.6 & -12.8 \\
NH private revenue (\$M) & 2.65 & -0.32 & -12.1 & -0.36 & -13.6 \\
NH Medicaid revenue (\$M) & 8.13 & +2.79 & +34.3 & -1.05 & -12.9 \\
NH profits (\$M) & 2.03 & -0.06 & -3.0 & +0.06 & +3.0 \\
NH residents on Medicaid, \% & 77 & +8 & +10.4 & 0 & -0.5 \\
\hline
\end{tabular}


Who fills up the new Medicaid beds? Table 10 shows that the new nursing home residents are coming from all but the top wealth quartile with larger numbers of new residents at the bottom. Most new residents trade the out-of-pocket HCBC for Medicaid nursing home. However, some $\mathrm{HCBC}$ recipients in the second wealth quartile become Medicaid HCBC recipients. Private residents leaving nursing homes due to its higher price belong to all but the bottom wealth quartile. They mostly switch to the out-ofpocket $\mathrm{HCBC}$, and this pattern is most noticeable at the top wealth quartile where Medicaid options are never chosen. The average number of care hours consumed also increases significantly, especially for the two bottom wealth quartiles, reducing the inequality in care consumption.

Medicaid expenditure increases by $\$ 25.8$ million (Table11, Panel A). Medicaid not only collects less wealth from each single recipient, but also faces an increase in recipiency by single households. This policy results in a small reduction in the producer surplus $(-\$ 600,000)$ and a relatively large increase in the consumer surplus $(+\$ 13.4$ million). However, the total surplus gain amounts only to a half of the increase in the Medicaid expenditure. The gains in the consumer surplus are not equally distributed across the households. The households in the second wealth quartile gain the most, as these are more likely to enter Medicaid when allowed to keep some of their wealth under the new policy. The gain at the top wealth quartile is limited. Though they value higher Medicaid insurance for situations with scant financial resources and no family support, they are less likely to be in such situations than the other wealth groups and are hurt by nursing homes' higher prices. 
Table 10: More generous Medicaid - effects on household care choices

\begin{tabular}{|c|c|c|c|c|c|c|}
\hline & \multicolumn{4}{|c|}{ Care type choice (\%) } & \multirow{2}{*}{\multicolumn{2}{|c|}{$\begin{array}{c}\text { Mean intensity } \\
\text { (hours per year) }\end{array}$}} \\
\hline & \multicolumn{2}{|c|}{ HCBC } & \multicolumn{2}{|c|}{ Nursing home } & & \\
\hline & Private & Medicaid & Private & Medicaid & All & $\begin{array}{l}\text { Private } \\
\text { HCBC }\end{array}$ \\
\hline \multirow[t]{2}{*}{ Age: $70-79$} & 57.6 & 14.1 & 3.7 & 24.7 & 2,019 & 1,967 \\
\hline & $(-4.8)$ & $(+0.8)$ & $(-0.8)$ & $(+4.9)$ & $(+146)$ & $(+171)$ \\
\hline \multirow[t]{2}{*}{ Age: $80-89$} & 54.6 & 15.1 & 4.2 & 26.1 & 2,109 & 2,125 \\
\hline & $(-6.8)$ & $(+1.4)$ & $(-1.1)$ & $(+6.4)$ & $(+163)$ & $(+213)$ \\
\hline \multirow[t]{2}{*}{ Age: $90-99$} & 56.7 & 13.3 & 5.0 & 25.0 & 1,850 & 1,664 \\
\hline & $(-9.1)$ & $(+2.3)$ & $(-1.5)$ & $(+8.3)$ & $(+192)$ & $(+183)$ \\
\hline \multirow[t]{2}{*}{ With family } & 58.2 & 14.6 & 2.1 & 25.1 & 2,090 & 2,092 \\
\hline & $(-8.0)$ & $(+1.8)$ & $(-0.7)$ & $(+6.9)$ & $(+180)$ & $(+227)$ \\
\hline \multirow{2}{*}{$\begin{array}{l}\text { Without } \\
\text { family }\end{array}$} & 49.2 & 13.1 & 11.5 & 26.3 & 1,674 & 1,233 \\
\hline & $(-3.5)$ & $(+0.7)$ & $(-2.8)$ & $(+5.6)$ & $(+129)$ & $(+97)$ \\
\hline \multirow[t]{2}{*}{ Wealth: Q1 } & 22.1 & 24.9 & 0.0 & 53.0 & 1,677 & 218 \\
\hline & $(-11.5)$ & $(-0.2)$ & $(0.0)$ & $(+11.6)$ & $(+258)$ & $(-52)$ \\
\hline \multirow[t]{2}{*}{ Wealth: Q2 } & 54.7 & 19.4 & 0.2 & 25.7 & 1,307 & 670 \\
\hline & $(-11.0)$ & $(+3.9)$ & $(-0.4)$ & $(+7.5)$ & $(+204)$ & $(+35)$ \\
\hline \multirow[t]{2}{*}{ Wealth: Q3 } & 85.5 & 3.2 & 7.0 & 4.4 & 1,385 & 1,262 \\
\hline & $(-1.1)$ & $(+1.6)$ & $(-2.8)$ & $(+2.3)$ & $(+79)$ & $(+63)$ \\
\hline \multirow[t]{2}{*}{ Wealth: Q4 } & $84.9^{\prime}$ & 0.0 & 15.1 & $0.0^{\prime}$ & 4,350 & 4,745 \\
\hline & $(+2.3)$ & $(0.0)$ & $(-2.3)$ & $(0.0)$ & $(+59)$ & $(-28)$ \\
\hline
\end{tabular}

Note: This table includes all individuals whose health is either ADLL or ADLH. The numbers in parentheses show the differences compared to the baseline.

In short, allowing singles to keep some amount of wealth while being on Medicaid increases the Medicaid expenditure more than it increases the consumer surplus, while the producer surplus reduces. The policy also creates significant distributional effects. Though the policy's direct impact is on the demand side, the nursing homes' reactions to the changing demand are important in shaping the distributional effects. The expanding pool of Medicaid patients would increase the nursing homes' profits in the absence of their reactions. However, competition among nursing homes on care intensity results in lower profits. Nursing home response, on the other hand, makes the new equilibrium favor poorer individuals as they enjoy more care 
hours without having to give up all of their financial resources, while the higher price disadvantages wealthier households.

Table 11: Demand-side targeted policy experiment outcomes - welfare evaluations

\begin{tabular}{|c|c|c|c|c|}
\hline \multirow[t]{2}{*}{ A. Aggregates } & \multicolumn{2}{|c|}{$\begin{array}{l}\text { Increased Medicaid } \\
\text { generosity }\end{array}$} & \multicolumn{2}{|c|}{$\begin{array}{l}\text { HCBC } \\
\text { subsidy }\end{array}$} \\
\hline & $\Delta$ level (\$M) & $\Delta \%$ & $\Delta$ level (\$M) & $\Delta \%$ \\
\hline Consumer surplus* & +13.4 & NA & +3.6 & NA \\
\hline Producer surplus & -0.6 & -3.0 & +0.6 & +3.0 \\
\hline Medicaid expenditures & +25.8 & +26.2 & -2.7 & -2.7 \\
\hline \multicolumn{5}{|l|}{ B. Distribution } \\
\hline Consumer surplus* & \multicolumn{2}{|c|}{$\begin{array}{c}\Delta \text { level } \\
\text { (per household, \$) }\end{array}$} & \multicolumn{2}{|c|}{$\begin{array}{c}\Delta \text { level } \\
\text { (per household, \$) }\end{array}$} \\
\hline Wealth: Q1 & \multicolumn{2}{|c|}{$+4,412$} & \multicolumn{2}{|c|}{+437} \\
\hline Wealth: Q2 & \multicolumn{2}{|c|}{$+11,368$} & \multicolumn{2}{|c|}{$+1,125$} \\
\hline Wealth: Q3 & \multicolumn{2}{|c|}{$+9,986$} & \multicolumn{2}{|c|}{$+3,092$} \\
\hline Wealth: Q4 & \multicolumn{2}{|c|}{$+1,624$} & \multicolumn{2}{|c|}{$+2,756$} \\
\hline
\end{tabular}

Note: The table presents the changes compared to the values in the baseline model.

* The consumer surplus is calculated as one-time wealth transfers needed to be made to the youngest households (age 70) in the baseline model to give them the same utility as with the policy experiment. The number in Panel $\mathrm{A}$ is the summation across households while those in Panel $B$ is the average within each wealth group.

\subsubsection{Subsidies for home-and-community-based care}

For individuals without family support, one big obstacle for using $\mathrm{HCBC}$ is the fixed cost of outsourcing home production as the adverse health condition does not allow them to perform basic home production (Achou 2016). In our model, this cost is captured by $\Psi$ and is calibrated as $\$ 20,000$ per year. This cost steers individuals without family away from using $\mathrm{HCBC}$ as a private patient. As a result, these individuals end up being Medicaid recipients and consuming amounts of care largely exceeding the levels they would have demanded as a private HCBC patient in the absence of the fixed cost, thus increasing Medicaid outlays. In this subsection, we consider a policy where 
government provides a lump-sum payment to cover half of the HCBC fixed cost $(\$ 10,000)$ to any non-Medicaid user of HCBC.

The direct impact of this policy is on the demand side, which reduces demand for nursing home care as individuals without family leave the nursing home market for the subsidized out-of-pocket HCBC. In the absence of the nursing homes' reactions, about three private residents (10.4\%) and 4.3 Medicaid residents $(4.4 \%)$ would leave each nursing home. Lost residents would reduce the profits of each nursing home by $\$ 160,000$.

How do nursing homes respond to the drop in demand? Theoretically, the effects on both price and care intensity are ambiguous. The channels governing nursing home incentives in response to the increased competition from $\mathrm{HCBC}$ are similar to the case of a nursing home's subsidized entry, discussed in Section 6.1.1. The main difference is in the direct effect on the private demand for care. While a nursing home entry makes the nursing home option more attractive, the opposite is true for the cheaper HCBC. Hence, it is unsurprising that the two experiments' effects are qualitatively similar up to the change in the number of the private nursing home residents and associated revenues and profits.

The last two columns of Table 9 show that the care intensity declines by 155 hours per year (-7.7\%) and price drops by $\$ 3,900$ (-4.5\%). Lower care intensity encourages more Medicaid nursing home residents to leave, bringing the total loss to 13.6 individuals $(-12.8 \%)$. On the contrary, lower price slightly reduces the loss of the private residents to $9.6 \%$. The lower quality and the smaller number of residents reduce the marginal cost by $\$ 5,900$, resulting in a higher profit on each resident. Though 
revenue from both private and Medicaid residents fall significantly $(-13.6 \%$ and $-12.9 \%$, respectively), profits increase slightly (3\%).

Table 12 shows that the new HCBC users come primarily from individuals of all ages and all wealth quartiles without family, with most leaving nursing home Medicaid beds. While individuals in the bottom quartile switch primarily to Medicaid HCBC, those in wealth quartiles two and three switch primarily to private HCBC. The mean hours of HCBC do not increase much for the individuals without family support: While those who chose this option in the baseline now can afford more hours, those who switch from Medicaid options to this option under the subsidy tend to be poorer and so consume fewer care hours than the former group. The average intensity of care used declines except for the top wealth quartile. This, on one hand, reflects a switch to out-of-pocket $\mathrm{HCBC}$, where individuals tend to have lower care intensity than in a nursing home. On the other hand, it also reflects the lower intensity of nursing home care than in the baseline. 
Table 12: HCBC subsidy - effects on household care choices

\begin{tabular}{|c|c|c|c|c|c|c|}
\hline & \multicolumn{4}{|c|}{ Care type choice (\%) } & \multirow{2}{*}{\multicolumn{2}{|c|}{$\begin{array}{l}\text { Mean intensity } \\
\text { (hours per year }\end{array}$}} \\
\hline & \multicolumn{2}{|c|}{ HCBC } & \multicolumn{2}{|c|}{ Nursing home } & & \\
\hline & Private & Medicaid & Private & Medicaid & All & $\begin{array}{l}\text { Private } \\
\text { HCBC }\end{array}$ \\
\hline \multirow[t]{2}{*}{ Age: $70-79$} & 63.7 & 14.5 & 4.3 & 17.6 & 1,836 & 1,795 \\
\hline & $(+1.3)$ & $(+1.2)$ & $(-0.2)$ & $(-2.2)$ & $(-37)$ & $(-1)$ \\
\hline \multirow[t]{2}{*}{ Age: $80-89$} & 63.3 & 14.6 & 4.8 & 17.3 & 1,906 & 1,905 \\
\hline & $(+1.9)$ & $(+0.9)$ & $(-0.5)$ & $(-2.4)$ & $(-40)$ & $(-7)$ \\
\hline \multirow[t]{2}{*}{ Age: $90-99$} & 68.5 & 11.5 & 5.8 & 14.2 & 1,611 & 1,478 \\
\hline & $(+2.7)$ & $(+0.4)$ & $(-0.7)$ & $(-4.0)$ & $(-47)$ & $(-3)$ \\
\hline \multirow[t]{2}{*}{ With family } & 66.8 & 14.1 & 2.7 & 16.4 & 1,882 & 1,867 \\
\hline & $(+0.6)$ & $(+1.3)$ & $(-0.1)$ & $(-1.8)$ & $(-28)$ & $(+2)$ \\
\hline \multirow{2}{*}{$\begin{array}{l}\text { Without } \\
\text { family }\end{array}$} & 59.3 & 11.8 & 12.4 & 16.5 & 1,459 & 1,162 \\
\hline & $(+6.4)$ & $(-0.6)$ & $(-1.9)$ & $(-4.2)$ & $(-86)$ & $(+26)$ \\
\hline \multirow[t]{2}{*}{ Wealth: Q1 } & 34.8 & 27.7 & 0.0 & 37.5 & 1,346 & 289 \\
\hline & $(+1.2)$ & $(+2.6)$ & $(0.0)$ & $(-3.9)$ & $(-73)$ & $(+17)$ \\
\hline \multirow[t]{2}{*}{ Wealth: Q2 } & 68.0 & 16.2 & 0.6 & 15.3 & 1,044 & 630 \\
\hline & $(+2.3)$ & $(+0.7)$ & $(0.0)$ & $(-2.9)$ & $(-59)$ & $(-5)$ \\
\hline \multirow[t]{2}{*}{ Wealth: Q3 } & 90.0 & 0.8 & 8.6 & 0.9 & 1,267 & 1,199 \\
\hline & $(+3.4)$ & $(-0.8)$ & $(-1.2)$ & $(-1.2)$ & $(-39)$ & $(0)$ \\
\hline \multirow[t]{2}{*}{ Wealth: Q4 } & 83.9 & 0.0 & 16.2 & 0.0 & 4,338 & 4,818 \\
\hline & $(+1.3)$ & $(0.0)$ & $(-1.2)$ & $(0.0)$ & $(+47)$ & $(+45)$ \\
\hline
\end{tabular}

Note: This table includes all the individuals whose health is either ADLL or ADLH. The numbers in parentheses show the differences compared to the baseline. 
The last two columns in Table 11, Panel A, indicate that the consumer surplus increases by $\$ 3.6$ million. Similar to the more generous Medicaid experiment, all wealth quartiles gain from the subsidy to HCBC (Panel B). However, the welfare gains are concentrated in the top half of the wealth distribution, who are more likely to use out-ofpocket $\mathrm{HCBC}$ and nursing home and benefit from their lower costs.

Perhaps somewhat surprisingly, the increase in the consumer surplus comes with no extra expenditures on the government program. In fact, Medicaid outlays, ${ }^{32}$ net of the cost of the new program, decline by $\$ 2.7$ million. Though the government is now subsidizes $\$ 10,000$ for each household without family that uses HCBC out of pocket, by doing so, at the same time, it reduces the number of more costly Medicaid residents. The budget savings from the latter (\$5.8 million) dominates the additional expenditure from the former ( $\$ 3.1$ million).

This policy experiment suggests that the fixed cost of using HCBC without family support is an important barrier. By reducing this barrier, the considered policy both reduces the expenditures of the government programs and increases the consumer surplus.

\section{Conclusion}

In this paper, we develop a structural model of a nursing home market that explicitly captures the households' LTC choices on the demand side and the nursing homes' choices of intensity and price of care on the supply side. The policy experiments

\footnotetext{
${ }^{32}$ We include the expenditure for the HCBC subsidy in the Medicaid expenditure for the ease of comparison with other experiments, though the subsidy might be administered through other government programs.
} 
considered in this paper show that to correctly evaluate policies' efficiency and distributional effects, it is important to take into account the interaction between the market's demand and supply sides. We show that whether the policy targets supply or demand side, both households and nursing homes' decisions are affected. Taking both responses into account results in much different equilibrium allocation of care and welfare gains or losses relative to the case when one side of the market is fixed. The structural model we develop should be useful for evaluating potential outcomes of a wide range of LTSS policies, especially those for which empirical evidence of effectiveness does not exists.

Although our framework is a step forward in the analyses of LTSS policies, we recognize its limitations and plan to address them in the future. Although our model captures rich heterogeneity on the household side - in age, income, wealth, health, and family status — for tractability, we abstracted from the heterogeneity on the nursing home side. Extending this model to incorporate policy-relevant nursing home heterogeneities - e.g., for-profit versus nonprofit (Hackmann 2019), high-end versus low-end — will be an important next step. Moreover, for the individuals with family nearby, we have taken the availability of family for care duties as given. The response of family to the costs of outside care options may also be important. 


\section{References}

Achou, Bertrand. 2016. "Disability in Retirement, Home Production, and Informal Insurance Between Spouses." Working Paper.

Achou, Bertrand. 2020. "Housing in Medicaid: Should It Really Change?" Working Paper.

Ameriks, John, Joseph Briggs, Andrew Caplin, Matthew D. Shapiro, and Christopher Tonetti. 2018. "Late-in-Life Risks and the Under-Insurance Puzzle." Vanguard Research Initiative Working Paper.

Ameriks, John, Joseph Briggs, Andrew Caplin, Matthew D. Shapiro, and Christopher Tonetti. Forthcoming. "Long-Term-Care Utility and Late-in-Life Saving." Journal of Political Economy.

Ameriks, John, Andrew Caplin, Steven Laufer, and Stijn van Nieuwerburgh. 2011. "The Joy of Giving or Assisted Living? Using Strategic Surveys to Separate Public Care Aversion from Bequest Motives." Journal of Finance 66: 519-61.

Barczyk, Daniel, and Matthias Kredler. 2018. "Evaluating Long-Term-Care Policy Options, Taking the Family Seriously." Review of Economic Studies 85: 766-809.

Barczyk, Daniel, and Matthias Kredler. 2019. "Long-Term Care Across Europe and the U.S.: the Role of Formal and Informal Care." Fiscal Studies 40: 329-73.

Braun, Anton, Karen Kopecky, and Tatyana Koreshkova. 2019. "Old, Frail, and Uninsured: Accounting for Features of the U.S. Long-Term Care Insurance Market." Econometrica 87: 981-1019.

Braun, R. Anton, Koren Kopecky, and Tatyana Koreshkova. 2017. "Old, Sick, Alone, and Poor: A Welfare Analysis of Old-Age Social Insurance Programs." Review of Economic Studies 84. 
Brown, Jeffrey R., and Amy Finkelstein. 2008. "The Interaction of Public and Private Insurance: Medicaid and the Long-Term Care Insurance Market." American Economic Review 98: 1083-1102.

Butrica, Barbara, and Nadia Karamcheva. 2014. "The Impact of Informal Caregiving on Older Adults' Labor Supply and Economic Resources." Urban Institute Report.

Ching, Andrew T., Fumiko Hayashi, and Hui Wang. 2015. "Quantifying the Impacts of Limited Supply: The Case of Nursing Homes." International Economic Review 56: 1291-1322.

Ettner, Susan L. 1994. "The Effects of the Medicaid Home Care Benefit on Long-Term Care Choices of the Elderly." Economic Inquiry 32: 103-27.

Genworth. 2019. Cost of Care Survey.

Gertler, Paul J. 1989. "Subsidies, Quality, and the Regulation of Nursing Homes." Journal of Public Economics 38.

Grabowski, David C. 2001. "Medicaid Reimbursement and the Quality of Nursing Homes." Journal of Health Economics 20: 549-69.

Grabowski, David C., and Jonathan Gruber. 2007. "Moral Hazard in Nursing Home Use." Journal of Health Economics 26.

Hackmann, Martin. 2019. "Incentivizing Better Quality of Care: The Role of Medicaid and Competition in the Nursing Home Industry." American Economic Review 109: 1684-1716.

Hurd, Michael D., Pierre-Carl Michaud, and Susann Rohwedder. 2014. "The Lifetime Risk of Nursing Home Use." In Discoveries in the Economics of Aging, edited by David A. Wise. University of Chicago Press. 
Johnson, Richard W., Cori E. Uccello, and Joshua H. Goldwyn. 2003. "Who Foregoes Survivor Protection in Employer-Sponsored Pension Annuities?" The Gerontologist 45: 26-35.

Jones, John, Mariacristina de Nardi, Eric French, Rory McGee, and Justin Kirschner. 2018. "The Lifetime Medical Spending of Retirees." NBER Working Paper 24599.

Kaiser Family Foundation. 2015. Medicaid and Long-Term Services and Supporters: A Primer.

Kaiser Family Foundation. 2016. Medicaid's Role in Meeting Seniors' Long-Term Services and Supports Needs.

Kopecky, Karen, and Tatyana Koreshkova. 2014. "The Impact of Medical and Nursing Home Expenses on Savings." American Economic Journal: Macroeconomics 6: 29-72.

Mommaerts, Corina. 2016. "Long-Term Care Insurance and the Family." Working Paper.

Mommaerts, Corina. 2018. "Are Coresidence and Nursing Homes Substitutes?

Evidence from Medicaid Spend-down Provisions." Journal of Health Economics 59: 125-38.

De Nardi, Mariacristina, Eric French, and John Bailey Jones. 2010. "Why Do the Elderly Save? The Role of Medical Expenses." Journal of Political Economy 118: 29-72.

De Nardi, Mariacristina, Eric French, and John Bailey Jones. 2016. "Medicaid Insurance in Old Age." American Economic Review 106.

De Nardi, Mariacristina, Eric French, John Bailey Jones, and Angshuman Gooptu. 2011. "Medicaid and the Elderly." NBER Working Paper 17689. 
Nyman, John A. 1985. "Prospective and 'Cost-Plus' Medicaid Reimbursement, Excess Medicaid Demand, and the Quality of Nursing Home Care." Journal of Health Economics 4.

Stabile, Mark, Audrey Laporte, and Peter C. Coyte. 2006. "Household Responses to Public Home Care Programs." Journal of Health Economics 25: 674-701.

U.S. Department of Health and Human Services. 2020. How Much Care Will You Need?

Warshawsky, Mark J., and Ross A. Marchand. 2017. "Improving the System of Financing Long-Term Services and Supports for Older Americans." Journal of Retirement 5: 48-68. 


\section{Appendix A: Estimation of the health transition matrices}

We use an approach based on Jones et al. (2018). The transition matrix from the current health state $\left(h_{t} \in\{A D L H, A D L L, B, G\}\right)$ to the next period's health state $\left(h_{t+1} \in\right.$ $\{D, A D L H, A D L L, B, G\})$ is obtained from multinomial logit estimation, which includes a constant, current health, gender, age, age squared, whether single or coupled, the permanent income of households, as well as interactions of these as the control variables. For permanent income, we create quartiles, and we use the dummy variable for each quartile.

To be specific, for each potential transition from $i \in\{A D L H, A D L L, B, G\}$ to $j \in$ $\{D, A D L H, A D L L, B, G\}$, the probability of that event is determined as:

$$
\begin{aligned}
\pi_{i j, t} & =\operatorname{Pr}\left(h_{t+1}=j \mid h_{t}=i\right) \\
& =\gamma_{i j} / \sum_{k} \gamma_{i k} \\
\gamma_{i D} & =1, \quad \forall i \\
\gamma_{i k} & =\exp \left(x_{h_{t}=i} \beta_{k}\right), k \in\{A D L H, A D L L, B, G\}
\end{aligned}
$$

where $\left\{\beta_{k}\right\}$ is the set of coefficient vectors and $x_{h_{t}=i}$ is the vector of the control variables with $h_{t}=i$. We estimate $\left\{\beta_{k}\right\}$ by MLE, using all HRS observations from 2004 to 2014 .

We present some examples of the estimated transition matrices in Table A1 (for age 70) and Table A2 (for age 90). Rows represent the current state and columns represent the next period's state. At age 70, a "Good" health is a persistent state and the more so for a woman and for those with high permanent income. At age 90, needing help with ADLs or death two years later becomes much more likely, even conditional on being "Good" in the current period. 
Table A1: Health transition matrix — for age 70, coupled

\begin{tabular}{ll|ccccc|ccccc}
\hline & & \multicolumn{4}{|c|}{ PI 1st quartile } & \multicolumn{5}{c}{ PI 4th quartile } \\
& & Death & ADLH & ADLL & Bad & Good & Death & ADLH & ADLL & Bad & Good \\
\hline Male & ADLH & 0.190 & 0.505 & 0.186 & 0.079 & 0.040 & 0.229 & 0.399 & 0.144 & 0.100 & 0.128 \\
& ADLL & 0.161 & 0.196 & 0.326 & 0.186 & 0.131 & 0.107 & 0.096 & 0.393 & 0.132 & 0.273 \\
& Bad & 0.103 & 0.069 & 0.107 & 0.496 & 0.225 & 0.096 & 0.035 & 0.118 & 0.433 & 0.318 \\
& Good & 0.036 & 0.024 & 0.057 & 0.137 & 0.746 & 0.018 & 0.010 & 0.039 & 0.066 & 0.867 \\
\hline Female & ADLH & 0.158 & 0.481 & 0.217 & 0.115 & 0.030 & 0.158 & 0.478 & 0.147 & 0.115 & 0.102 \\
& ADLL & 0.100 & 0.179 & 0.329 & 0.265 & 0.127 & 0.059 & 0.117 & 0.369 & 0.159 & 0.297 \\
& Bad & 0.062 & 0.057 & 0.146 & 0.552 & 0.183 & 0.054 & 0.042 & 0.160 & 0.435 & 0.309 \\
& Good & 0.023 & 0.022 & 0.057 & 0.140 & 0.759 & 0.009 & 0.011 & 0.033 & 0.051 & 0.896 \\
\hline
\end{tabular}

Table A2: Health transition matrix - for age 90, coupled

\begin{tabular}{|c|c|c|c|c|c|c|c|c|c|c|c|}
\hline & \multicolumn{5}{|c|}{ PI 1 ${ }^{\text {st }}$ quartile } & \multicolumn{5}{|c|}{ PI $4^{\text {th }}$ quartile } \\
\hline & & Death & ADLH & ADLL & Bad & Good & Death & ADLH & ADLL & Bad & Good \\
\hline \multirow[t]{4}{*}{ Male } & ADLH & 0.497 & 0.417 & 0.060 & 0.009 & 0.017 & 0.531 & 0.387 & 0.048 & 0.009 & 0.026 \\
\hline & ADLL & 0.412 & 0.248 & 0.187 & 0.057 & 0.096 & 0.326 & 0.191 & 0.311 & 0.045 & 0.126 \\
\hline & Bad & 0.293 & 0.168 & 0.099 & 0.233 & 0.207 & 0.318 & 0.133 & 0.147 & 0.221 & 0.180 \\
\hline & Good & 0.191 & 0.133 & 0.092 & 0.104 & 0.480 & 0.164 & 0.123 & 0.126 & 0.080 & 0.507 \\
\hline \multirow[t]{4}{*}{ Female } & ADLH & 0.448 & 0.434 & 0.092 & 0.013 & 0.013 & 0.397 & 0.507 & 0.064 & 0.011 & 0.021 \\
\hline & ADLL & 0.291 & 0.259 & 0.260 & 0.093 & 0.097 & 0.189 & 0.248 & 0.374 & 0.057 & 0.132 \\
\hline & Bad & 0.197 & 0.156 & 0.181 & 0.293 & 0.172 & 0.187 & 0.165 & 0.249 & 0.232 & 0.166 \\
\hline & Good & 0.132 & 0.132 & 0.124 & 0.118 & 0.494 & 0.093 & 0.151 & 0.146 & 0.071 & 0.539 \\
\hline
\end{tabular}

